\title{
FOXO factors and breast cancer: outfoxing endocrine resistance
}

\section{Bullock}

Hormones and Cancer Group, Cancer Genetics Laboratory, Kolling Institute of Medical Research, Royal North Shore Hospital, Pacific Highway Saint Leonards, Sydney, New South Wales 2065, Australia
Correspondence should be addressed to M Bullock Email martyn.bullock@ sydney.edu.au

\begin{abstract}
The majority of metastatic breast cancers cannot be cured and present a major public health problem worldwide. Approximately $70 \%$ of breast cancers express the estrogen receptor, and endocrine-based therapies have significantly improved patient outcomes. However, the development of endocrine resistance is extremely common. Understanding the molecular pathways that regulate the hormone sensitivity of breast cancer cells is important to improving the efficacy of endocrine therapy. It is becoming clearer that the PI3K-AKTforkhead box O (FOXO) signaling axis is a key player in the hormone-independent growth of many breast cancers. Constitutive PI3K-AKT pathway activation, a driver of breast cancer growth, causes down-regulation of FOXO tumor suppressor functions. This review will summarize what is currently known about the role of FOXOs in endocrine-resistance mechanisms. It will also suggest potential therapeutic strategies for the restoration of normal FOXO transcriptional activity.
\end{abstract}

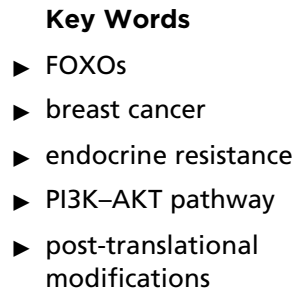

Endocrine-Related Cancer (2016) 23, R113-R130

\section{Introduction}

Breast cancer is a leading cause of female death worldwide. Each year, almost 1.4 million women are diagnosed with breast cancer, and the disease will be responsible for 450000 deaths (Siegel et al. 2011). This review will highlight the importance of forkhead box O (FOXO) activity in the development of endocrine resistant breast cancer. FOXO transcription factors are key regulators of gene expression in numerous physiological and pathological processes. FOXO nuclear exclusion is a key feature of breast cancer cells transformed by oncogenic PI3K-AKT signaling (Zhang et al. 2011, Fig. 1). It is also becoming clear that aberrant FOXO activity promotes a number of characteristic features of hormone-independent breast cancer growth, including altered estrogen receptor (ER) function. Although breast cancer cells express multiple FOXOs, most studies have focused on the FOXO3A isoform. FOXOs are subject to extensive post-translational regulation, and targeting these processes may provide therapeutic strategies to overcome resistance.

\section{FOXO gene family}

The FOXO genes encode for the O-subfamily of proteins that belong to the larger family of forkhead transcription factors. Forkhead transcription factors are named after the Drosophila melanogaster forkhead gene ( $f k h$; Weigel et al. 1989), and to date, 200 members have been identified; in species that range in complexity from Saccharomyces cerevisiae that has four members (Wijchers et al. 2006) to human with 43 members (Katoh \& Katoh 2004). These proteins are characterized solely by the presence of a highly conserved DNA-binding domain (DBD) called the

Published by Bioscientifica Ltd. 


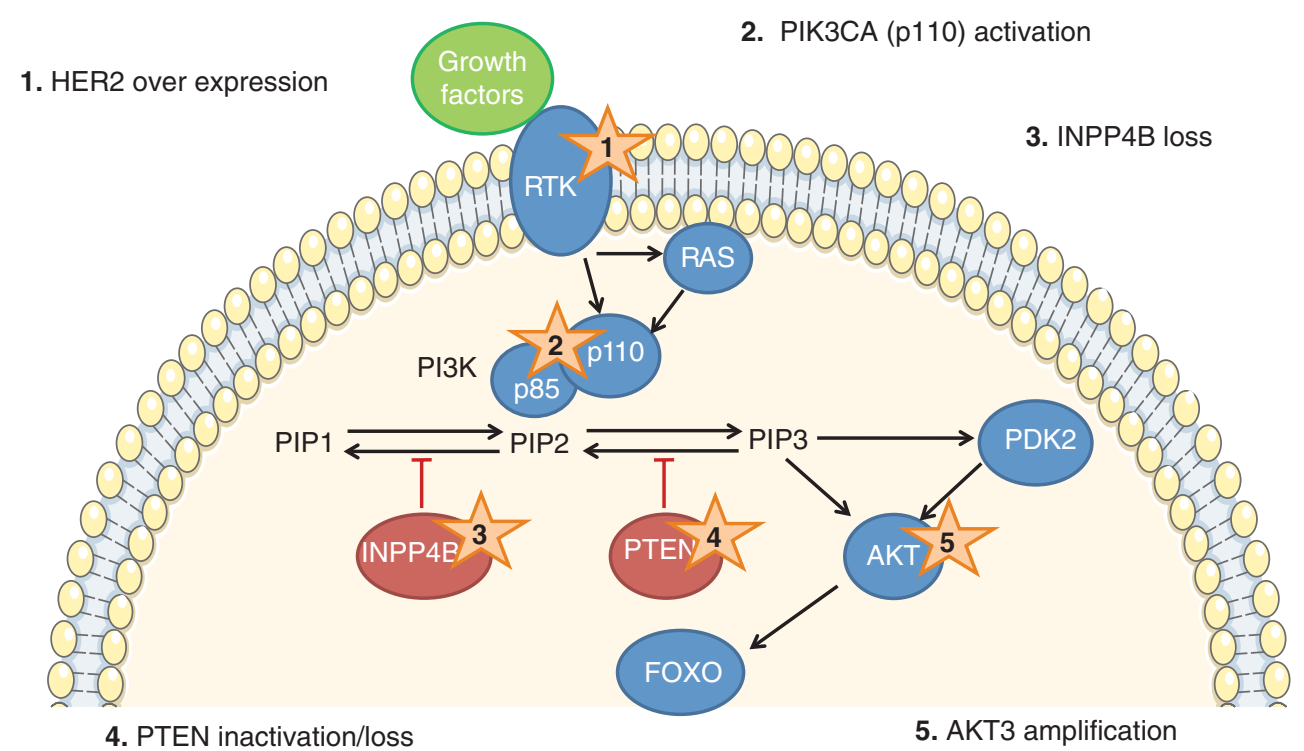

\section{Figure 1}

Genetic changes found in different forms of breast cancer that cause chronic activation of the PI3K-AKT pathway. Afflicted components of the pathway are highlighted, and the specific nature of the most common

FOX, forkhead (FKD) (Weigel \& Jackle 1990), or alternatively the winged-helix domain (Gajiwala \& Burley 2000). On the basis of minor sequence variation within the FOX-domain, FOX family members are divided into sub-families, that are each designated with a different letter (currently there are 17 subfamilies, ranging from A to Q). Outside of the FOX-domain, there is little shared homology, and the structure and function of FOX proteins is found to be incredibly diverse. As is the case for members of all large transcription factor families, FOX genes been implicated in the transcriptional regulation of an extensive range of biological processes. In the case of FOX genes, such reported functions include regulation of cell proliferation, differentiation, DNA-repair, apoptosis, metabolism, and also immuneregulation (Lam et al. 2006, Wijchers et al. 2006, Ziegler 2006, Laoukili et al. 2007).

In mammalian species, there are four members of the FOXO gene family. Three of the members exhibit a high degree of sequence homology: FOXO1 (previously called FKHR), FOXO3A (FKHRL1), and FOXO4 (AFX). The fourth member of the family, the FOXO6 gene, exhibits major structural differences compared with the other three family members.

In keeping with a high degree of sequence homology between DBDs shared by members of the same forkhead mutations described: (1) HER2 receptor amplification; (2) PI3CA (p110) activating mutations; (3) deletion of INPP4B gene; (4) PTEN inactivating mutations/deletions; and (5) AKT1/AKT3 activating mutations.

subfamily, all FOXO proteins share the same DNAbinding specificity, recognizing gene regulatory elements that share a central core DNA motif consisting of the nucleotides TTGTTTAC. Profiling of genome-wide FOXO DNA-binding has been mostly been performed in the study of the immune-system, with FOXO cistrome having been determined for B-cells and macrophages. (Fan et al. 2010, Lin et al. 2010, Litvak et al. 2012). These studies are somewhat limited in their ability to determine direct downstream effects of FOXO activity. However, Eijkelenboom et al. (2013) used an inducible cell-culture system (DLD1 colon carcinoma cells) to measure the direct effects of FOXO3A activation. Analysis of the FOXO3A cistrome reveals that the factor functions predominantly as a classical transcriptional activator. Furthermore, a significant part of FOXO3A gene-regulation is found to proceed through enhancer regulatory elements.

FOXOs are expressed throughout the human body, and there is broad overlap in their expression patterns. However, each factor is uniquely enriched within particular tissue types: FOXO1 in adipose and liver tissue, FOXO3A in the brain, and FOXO4 in skeletal muscle. Uniquely, the FOXO6 gene appears to be expressed almost exclusively in adult brain (Furuyama et al. 2000). Despite tissue specific enrichment, there clearly exists some level

Published by Bioscientifica Ltd 
of functional redundancy between FOXO factors, with the net activity of multiple co-expressed FOXOs having an accumulative effect on gene expression. This is highlighted by observations drawn from compound geneknockout experiments. Initially, such studies that utilized single- or double-knockouts to disrupt one or two FOXO factors did not yield the expected tumor-prone phenotype (see the section covering 'Tumor suppressor function of FOXOs'). However, broad somatic-cell deletion of all three FOXO factors yields the full tumor phenotypes characterized by thymic lymphomas and hemangiomas (Castrillon et al. 2003, Hosaka et al. 2004, Paik et al. 2007). Strikingly, despite widespread expression of FOXOs throughout the body, carcinogenesis is restricted to thymocytes and endothelial-derived cell lineages in this model. At present it is not clear why this is the case. Interestingly, hemangiomas are a characteristic feature of Cowden's disease, which is caused by germline inactivation of the phosphatase and tensin homolog (PTEN) gene, leading to hyperactivity of the PI3K-AKT pathway. The mechanism by which constitutive PI3K-AKT pathway activation causes down-regulation of FOXO activity is discussed in more detail below.

\section{Tumor suppressor function of FOXOs}

Interestingly, FOXO1, 3, and 4 were implicated in cancer biology immediately upon their discovery. FOXO1 was discovered as a fusion protein (the fusion partner being either the PAX3 or PAX7 DBD), the product of a chromosomal translocation event within the cells of pediatric alveolar rhabdomyosarcoma (Galili et al. 1993, Sublett et al. 1995, Schmitt-Ney \& Camussi 2015). FOXO3A and FOXO4 were discovered as fusion partners with the mixed-lineage leukemia gene in acute myeloid leukemias (Parry et al. 1994). However, experiments that attempted to recapitulate a tumor phenotype by overexpressing these fusion proteins were largely unsuccessful (Lagutina et al. 2002), suggesting instead that loss of FOXO function might be the crucial step in mediating carcinogenesis. It is now clear that FOXOs are tumor-suppressors, and suppression of their activity contributes to a number of malignant processes. For instance, FOXOs are well characterized as transcriptional regulators of a large number of genes implicated in carcinogenesis. These include: i) cell-cycle regulatory components such as p $27^{\mathrm{kip} 1}$ (CDKN1B; Dijkers et al. 2000); ii) pro-apoptotic proteins like TRAIL (TNFSF10; Modur et al. 2002); iii) DNA repair enzymes such as GADD45 (Kobayashi et al. 2005); iv) detoxification pathway enzymes such as manganese superoxide dismutase 2 (Adachi et al. 2007); and v) genes involved in autophagy and the maintenance of cellular organelle and protein homeostasis (Webb \& Brunet 2014).

\section{Breast cancer and hormone dependence}

There are four recognized major molecular subtypes of breast cancer, which are classed according to gene expression profiling (Perou et al. 2000). The vast majority of breast cancers $(\sim 70 \%)$ are ER positive $(\mathrm{ER}+)$. They belong to either the Luminal-A group (mostly ER + and histologically low grade); or the luminal-B group (mostly $\mathrm{ER}+$ and often higher grade). Endocrine therapy is the most efficacious treatment for these forms of breast cancer. The human epidermal growth factor receptor 2 (HER2, expressed by the ERRB gene)-amplified group, have been a great clinical success due to the development of effective HER2-targeting therapies (Bergamaschi et al. 2006, Chin et al. 2006). In contrast, the triple-negative breast cancer group (also known as basal-like breast cancers), so-called because they lack expression of ER, progesterone receptor (PR), and HER2, are a patient group who currently only have chemotherapy options (Perou 2011).

\section{Endocrine therapy}

The growth and development of normal breast tissue is governed by the signaling action of the ovarian hormones, $17 \beta$-estradiol $\left(\mathrm{E}_{2}\right.$, the predominant estrogen) and progesterone, which signal through the nuclear receptors ER and PR respectively. Two major isoforms of ER exist, ER $\alpha$ and ER $\beta$, which are encoded by separate genes, ESR1 and ESR2 (ER1 and ER2) respectively (reviewed by Jia et al. (2015)). The PR also exists as two isoforms, PR-A and PR-B, the products of transcription from two alternative promoters of the PR (PGR) gene (reviewed by Jacobsen \& Horwitz (2012)). Immunohistochemical analysis of normal breast tissue, obtained from pre-menopausal women, shows that ER $\alpha$, PR-A, and PR-B are expressed within the inner luminal epithelial layer of the acini and intralobular ducts, and also the myoepithelial layer of the interlobular ducts (Li et al. 2010). ER $\beta$ exhibits a more widespread expression pattern, being found within the epithelial, myoepithelial, and stromal cells of both acini and ducts. Normal growth of female breast tissue occurs during puberty, during the menstrual cycle and also during pregnancy; with $\mathrm{E}_{2}$ regulating the process of ductal elongation and branching (Deroo et al. 2009), and progesterone regulating side-branching, and lobular development (Conneely et al. 2007). The expression levels

Published by Bioscientifica Ltd. 
of ER and PR isoforms are also dynamically regulated during these processes (Arendt \& Kuperwasser 2015). The classic function of ligand activated $\mathrm{ER} \alpha$ is transcriptional regulation of hundreds of genes involved in processes such as proliferation, differentiation, survival, invasion, many of which are particularly relevant for cancer biology.

Seventy percent of all breast cancers exhibit detectable expression of the ER $\alpha$ and/or the PR (the role of PR is reviewed in depth by Brisken (2013) and Seton-Rogers (2015)). A plethora of studies have demonstrated that $\mathrm{ER} \alpha$-signaling functions as a major driver of breast cancer tumorigenesis; promoting cancer-cell proliferation, survival, and invasive behavior (Osborne \& Schiff 2011). In contrast ER $\beta$ is expressed in $50 \%$ of breast cancers (Borgquist et al. 2008), and it appears to possess ER $\alpha$ independent function in breast cancer; but it remains much less well characterized, and studies have yielded conflicting results regarding its clinical significance (reviewed by Burns \& Korach (2012)). In this review, ER will refer to the $\mathrm{ER} \alpha$ isoform, unless otherwise stated.

Clinically, when compared with the behavior of ER-negative (-) cancers, affected patients are more likely to present with indolent disease, bone metastases, and late disease reoccurrence (Blanco et al. 1990). However, in contrast with triple-negative breast cancers, endocrine therapies that target and inhibit ER function, mean that $\mathrm{ER}+$ breast cancer patients have more effective treatment options available to them.

Currently, three broad classes of endocrine therapy are commonly used to treat ER + breast cancers: i) selective ER modifiers, e.g., tamoxifen, which binds directly to the ER and inhibits its transcriptional activity; ii) selective ER down-regulators, e.g., fulvestrant, which bind to the ER and induce its degradation; and iii) aromatase inhibitors (AIs), e.g., letrozole, anastrozole (both non-steroidal/ reversible) and excemestane (steroidal/irreversible), which act to inhibit aromatase enzymes expressed throughout peripheral tissues and the tumor itself, thus reducing the production, and therefore circulating levels of estrogen. Endocrine therapy has been successful, and the outcome for millions of breast cancer patients has been significantly improved over the past 30 years (Bliss et al. 2012).

\section{Endocrine resistance}

Although long-term remission is possible, a significant proportion of patients will develop some form of resistance to endocrine therapy. Four commonly occurring clinical scenarios are as follows: i) the breast cancer initially responds positively to endocrine therapy, but eventually acquires resistance. Often, in such cases, additional positive responses can be temporally gained from the use of alternative endocrine therapies; however, the cancer eventually evolves resistance to all therapy; ii) disease progression following an initial response to endocrine therapy, followed by a renewed response to the same therapy when administered years later; iii) de novo resistance to all endocrine therapies, or the acquisition of this resistance soon after the patient begins adjuvant treatment; and iv) de novo resistance to some, but not all therapies. There is pre-clinical data to suggest that de novo and acquired forms of resistance share common pathways (see section discussing 'Preclinical studies'). However, some clinical scenarios also support the existence of drug (or class of drug)-specific forms of resistance.

\section{FOXOs in breast cancer}

FOXO3A appears to be a key isoform in mediating hormone-independent breast cancer growth. FOXO3A overexpression significantly inhibits the growth of breast tumors in vitro and in animal models (Hu et al. 2004, Yang et al. 2008, Zou et al. 2008), and also negatively impacts upon angiogenesis; a process required for malignant tumor growth, invasion, and metastasis (Potente et al. 2005). Hu et al. (2004) observed that cytoplasmic FOXO3A staining correlated with the expression of inhibitor of nuclear factor kappa-B kinase subunit beta (IKK $\beta)$, raised phospho-AKT and overall poorer patient survival. Gargini et al. (2015) showed that FOXO proteins, in concert with Bim (a member of the BCL2 protein family), mediate the PI3K-AKT driven cancer stem-cell phenotype within three commonly used breast cancer cell-lines (MDA-MB-231, MCF7-Ras, and MCF10A) (Gargini et al. 2015). Furthermore, Lv et al. (2013) found that C-terminus of Hsc70interacting protein induced apoptosis resistance to chemotherapeutics in normal and breast cancer cells, specifically by modulation of the PI3K-AKT-FOXO3ABim signaling axis (Lv et al. 2013).

\section{Interaction between FOXOs and ER signaling}

The function of FOXO3A as a tumor repressor appears to be dependent on the co-expression of ER. Sisci et al. (2013) observed that overexpression of FOXO3A induces a decrease in the malignant behavior (motility, invasiveness, and anchorage-independent growth) of an in vitro ER + cancer cell model, while eliciting the opposite effect in ER - (or ER-silenced) cell-lines. Immunohistochemical analysis performed in the same study revealed that on the

Published by Bioscientifica Ltd. 
one hand, nuclear FOXO3A staining inversely correlated with invasive phenotype of ER + breast tumors, but on the other hand positively correlated with invasion of ER - tumors.

This ER-dependent tumor repressor activity of FOXOs can be explained, at least partly, by their role as the mediators of crosstalk between ER and growth factor receptor signaling. Several reports have recently suggested a functional interaction between ER and FOXO family members. Estrogen-activated ER binds to FOXO1, FOXO3A, and FOXO4; which depending on the cellular context, exhibit co-activator or co-repressor functions on estrogen-responsive DNA regulatory elements (Schuur et al. 2001, Zhao et al. 2001, Zou et al. 2008). Interestingly, ER has also shown to interact with a diverse number of FOX proteins including FOXE1 (Park et al. 2012), FOXP1 (Halacli \& Dogan 2015), and FOXA1 (Wright et al. 2014); suggestive of a conserved mechanism of association between the receptor and the wider forkhead family. The significance of the ER-FOX interaction is highlighted by the role of FOXA1 as a pioneer factor, which facilitates ER DNA-binding at cis-regulatory elements within heterochromatin. Indeed, FOXA1 expression is positively correlated with a good prognosis of ER + breast cancers, probably because FOXA1 expression is indicative of a functional ER (reviewed in depth by Tokunaga et al. (2014)).

Currently, no data exists to whether the potential pioneer activity FOXOs (reviewed by Lalmansingh et al. (2012)) can also modulate ER DNA-binding in breast cancer. However, Morelli et al. (2010) demonstrated that FOXO3A, functioning as a classical co-repressor of ER, could exert a protective role in $\mathrm{ER}+$ breast tumors. In agreement with this observation, targeted inhibition of AKT isoform 2 activity in these cells inhibited ER-directed transcription via FOXO3A activation.

\section{Other molecular mechanisms of endocrine resistance}

HER2 amplification is a well-established marker for endocrine resistance (Arpino et al. 2004). A meta-analysis showed that HER2 + metastatic breast cancers are less responsive to all forms of endocrine therapy (De Laurentiis et al. 2005). The molecular mechanisms of HER2 mediated hormone resistance are becoming clearer. HER2containing heterodimers, particularly HER2-HER3 heterodimers, induce PI3K-AKT pathway activation (Tzahar et al. 1996), and HER2 amplification is positively correlated with AKT activity in breast carcinomas (Stal et al. 2003, Zhou et al. 2004, Tokunaga et al. 2006). However, <10\% of
$\mathrm{ER}+$ breast cancers are also HER $2+$. Thus, the underlying resistance mechanism(s) for the majority of ER+ breast cancers remains to be elucidated.

Pre-clinical studies have implicated growth factor signaling pathways in the estrogen-independent activation of ER. In addition to HER2, tyrosine receptor kinases implicated in the development of endocrine resistance include: epidermal growth factor receptor (EGFR), insulin-like growth factor receptor 1 (IGF1R), insulin receptor, receptor originated from nantes, and fibroblast growth factor receptor 1 (Frogne et al. 2009, McClaine et al. 2010, Turner et al. 2010, Fox et al. 2011). All of these receptors converge on the PI3K-AKT signaling pathway, hyper-activation of which promotes the acquired estrogen-independent growth of ER + breast cancer cells (Miller et al. 2010). They also activate the rat sarcoma viral oncogene homolog (RAS)/ERK signaling pathway, contributing to estrogen-independent ER activation; even in cultured breast cancer cells that are grown in the presence of tamoxifen. Under these conditions, ERK phosphorylates ER at serine 118 (Ser118), a site that is normally phosphorylated in response to estrogenstimulation; itself an ERK-independent mechanism (Kato et al. 1995, Bunone et al. 1996).

In addition to perturbed growth factor signaling, another mechanism of endocrine resistance involves the inhibition of transcriptional co-activators, such as steroid receptor co-activator 1 , that interacts with ER (Shang \& Brown 2002). Decreased interactions between ER and the nuclear receptor co-repressor can also lead to tamoxifen resistance (Lavinsky et al. 1998). Indeed, Shang et al. (2000) showed that tamoxifen recruits co-repressors to ER-responsive gene promoters, but not co-activators.

Autophagy, the process by which a cell degrades and recycles damaged or unrequired organelles, has also recently been revealed to play a central role in endocrine resistance. The unfolded protein response (UPR) is an evolutionary conserved stress-responsive pathway, activated when unfolded or misfolded proteins accumulate within the cells endoplasmic reticulum. The master regulator of ubiquitin specific peptidase (USP) signaling is the protein chaperone glucose-regulated protein 78 (GRP78), which integrates signals from several pathways to concurrently inhibit stress-induced apoptosis and stimulate a prosurvival autophagic response (Cook et al. 2012, Clarke \& Cook 2015). Elevated GRP78 expression has been observed within all breast cancer molecular subtypes, as compared with the levels of expression in normal breast tissue (Cook et al. 2012). Within breast cancer cells GRP78 controls the autophagic response via

Published by Bioscientifica Ltd. 
signaling through the $5^{\prime}$-AMP-activated protein kinase and mammalian target of rapamycin (mTOR) signaling pathways (Cook et al. 2012). Cook et al. (2014) observed that treatments such as tamoxifen and fulvestrant can stimulate the pro-survival UPR and autophagy signaling in breast cancer cells.

\section{De-regulation of PI3K-AKT signaling in breast cancer}

Constitutive activation of PI3K-AKT signaling is recognized as a major driver of cancer progression. Dysregulation of the pathway has been implicated in an extensive range of human malignancies; including breast, ovarian, head and neck, and colorectal cancer. It is also a central player in the mechanisms leading to endocrine resistance of breast cancer (Tokunaga et al. 2014). Several causal mechanisms have been reported; all consequent to DNA mutations in genes encoding principal components of the pathway (see Fig. 1). The exact nature and frequency of mutation is unique to each type of cancer (Thorpe et al. 2015).

The PI3K-AKT pathway is extremely well characterized and has been reviewed in considerable detail by others (Fruman \& Rommel 2014, Martini et al. 2014, Thorpe et al. 2015). Briefly, the PI3K protein/lipid kinases are grouped into classes I (which itself is further divided into IA and IB), II, or III according to their structure and specific substrate specificity. The best characterized of these are class IA PI3Ks, which are heterodimeric; each composed of a catalytic subunit (p110) and a regulatory adaptor protein (p85). They function to transduce input signals from a wide variety of upstream sources, such as growth factor/hormone stimulated-receptor tyrosine kinases (RTKs), G-protein coupled receptors, and also oncogenic signaling molecules such as RAS.

The p110 catalytic subunit has three isoforms: p110 $\alpha$, $\mathrm{p} 110 \beta$, and $\mathrm{p} 110 \delta$ that are encoded for by three individual genes; PIK3CA, PIK3CB, and PIK3CD respectively. The $\mathrm{p} 85$ regulatory subunit also has three isoforms: p $85 \alpha, \mathrm{p} 55 \alpha$, and $\mathrm{p} 110 \delta$ which are also transcribed from three different genes; PIK3R1, PIK3R2, and PIK3R3 respectively.

Following growth factor/hormone activation of a RTK, the p85 subunit binds via its SH2-domain to the phosphorylated-protein motifs of the RTK. This recruitment has the effect of lifting p85-mediated inhibition of the p110 subunit, allowing p85 to catalyze conversion of phosphatidylinositol 4,5-bisphosphate (PIP2) into phosphatidylinositol 3,4,5-trisphosphate (PIP3). The tumor suppressor gene PTEN encodes a phosphatase that removes phosphate from PIP3; and thus functions as a negative regulator of the PI3K-AKT pathway. Another phosphatase with tumor-suppressor function is inositol polyphosphate-4-phosphatase, type II (INPP4B), the gene product of which also negatively regulates the pathway, by depleting cellular levels of PIP2. Upon generation, PIP3 functions as a secondary messenger, attaching to the pleckstrin-homology-domain of proteins such as v-akt murine thymoma viral oncogene homolog 1 (AKT) and pyruvate dehydrogenase kinase isoform 1. PIP3 binding to AKT targets this Ser/threonine (Thr) kinase to the cellmembrane where it can be activated by phosphorylation at Ser473 by mTOR, and then at Thr308 by phosphoinositide dependent kinase 1 . AKT activation initiates cascades of downstream phosphorylation events that impact on several aspects of cellular behavior that are of relevance to cancer; including cell cycle progression, enhanced chemotherapeutic resistance, elevated cell metabolism, increased resistance to hypoxia, and tumor metastasis.

According to The Cancer Genome Atlas PIK3CA is frequently mutated gene in breast cancer, present at a frequency of 49 and $32 \%$ in ER+ luminal $\mathrm{A}$ and $\mathrm{B}$ subtypes; $42 \%$ of HER2-enriched, and $7 \%$ of basal-like breast cancer subtypes. Other mutations impacting upon PI3K-AKT pathway activity, such as PTEN mutation/loss and INPP4B loss were also commonly found in all four subtypes (Cancer Genome Atlas N 2012). Recent studies have reported that alterations to the AKT3 gene (e.g. the MAGI-AKT3 gene fusion), leading to constitutive AKT activation, also occur in some ER + and triple-negative breast cancers (Kirkegaard et al. 2010, Banerji et al. 2012, O'Hurley et al. 2014).

The PI3K-AKT pathway can also be activated via signaling crosstalk with the ER. The ER binds to the p85 regulatory subunit of PI3K, in an estrogen-dependent manner, resulting in downstream activation of AKT (Simoncini et al. 2000). The treatment of breast cancer cells with $\mathrm{E}_{2}$ stimulates cellular proliferation via PI3K-AKT pathway activation (Lee et al. 2005). Interestingly, this activity was found to be ER $\alpha$-dependent, while ER $\beta$ appears not to play a role.

\section{The role of PI3K-AKT-FOXO signaling in breast cancer}

Mechanisms of FOXO regulation Cancer associated FOXO dysregulation activity can arise from genetic mutations (chromosomal translocation; described above) or through disruption of their transcriptional activity. In-keeping with the pleiotropic functioning of FOXOs, their activity is subjected to a variety of different regulatory mechanisms depending upon the cellular

Published by Bioscientifica Ltd. 
context. These can be broadly divided into those which are exerted at the transcriptional level, and those which involve post-translational modifications.

Transcriptional regulation of FoxOs Recent studies have suggested that the expression of FOXO1 and FOXO3A is subjected to modulation at the gene-promoter level by the transcription factor E2F1. Nowak et al. (2007) found that E2F1, in a glioblastoma in-vitro model, induced the transcription of both of FOXO1 and FOXO3A. Both gene promoters contained evolutionary conserved E2F1 binding-sites, and therefore, they are highly likely to be direct targets of E2F1. Interestingly, the ER regulated E2F1 expression has been associated with tamoxifen resistance in ER + breast cancer cells (Montenegro et al. 2014).

FOXO gene transcription is regulated by nutrient intake and insulin signaling in an in vivo insulin resistance model. Reduced nutrient availability in an artificially induced insulin-resistance state, stimulated transcription of FOXO1, FOXO3A, and FOXO4 in rat hepatocytes (Imae et al. 2003). Recently, observations of an in vivo model of fasted blood glucose revealed the cAMP-protein kinase A (PKA) stimulated transcriptional co-activator p300 induces transcription of FOXO1 (Wondisford et al. 2014).

Post-translational regulation of FOxO activity Post-translational protein modification of FOXOs has been extensively studied, and it is apparent the function of these factors is subjected to multiple layers of regulation. Although, apparently complex, FOXO post-translational regulation appears to operate by modulating two complementary mechanisms: i) altered FOXO subcellular localization and ii) modulation of FOXO DNA-binding and/or association with other DNA-binding proteins. The net action of these processes can profoundly impact upon FOXO-regulated gene transcription. Outlined below are the most extensively characterized FOXO protein modifications:

Phosphorylation Brunet et al. (1999) discovered that FOXOs were subject to regulation by the PI3K-AKT signaling pathway. They demonstrated that AKT possesses high binding affinity for the FOXO3A protein motif RXRXXS/T, and upon binding to the FOXO factor, catalyzes the phosphorylation of three specific amino-acids: Thr32, Ser253, and Ser315. All FOXO proteins, with the exception of FOXO6, contain evolutionary conserved variants of these phosphorylation sites (see Fig. 2). The phosphorylated-FOXO3A isoform is subsequently translocated out of the nucleus and sequestered in the cytoplasm. Each of the three phosphorylation events contributes to this translocation by a different mechanism. Phosphorylated Thr32 is directly involved in regulating the binding of 14-3-3 chaperone proteins (Brunet et al. 2002). The residue Ser253 resides within a nuclear localization sequence (NLS), and the addition of a negatively charged phospho-group to this basic sequence physically disrupts the signal, and inhibits the re-entry of cytoplasmic FOXOs into the nucleus. In contrast, Ser315 phosphorylation results in the unmasking of a nuclear export sequence (NES), which mediates physical association with the exportin chromosome region maintenance 1 (CRM1; also known as exportin-1 or Xpo1 protein). Thus, cultured cells treated with the CRM1 inhibitor leptomycin exhibit predominant FOXO nuclear localization and this inhibition of nuclear export is independent of FOXO phosphorylation status (Brunet et al. 2002). The importance of the NES is also highlighted by the behavior of FOXO6, which is the only FOXO to lacks the NES, and unlike the other three subfamily members; it is predominantly a nuclear protein (Jacobs et al. 2003).

Other inhibitory kinases The conserved RXRXXS/T protein motif also serves as a binding-substrate for several other kinases such as PKA, PKC, and serum and glucocorticoidinduced kinase (SGK; Pearce et al. 2010). Thus, several growth factors signaling converge on the FOXOs to negatively regulate their function. Interestingly, in vitro experiments utilizing dominant-negative mutant forms of AKT or SGK, inhibiting their respective pathways, both lead to nuclear accumulation of FOXOs; suggesting a nonredundant role for at least some kinases in targeting FOXOs to the cytoplasm (Brunet et al. 2001). It remains unclear why such redundancy exists, but it may be the case that the activity of each kinase is specific to a particular physiological/cellular context.

ERK phosphorylates FOXO3A on the amino-acid residues: Ser294, Ser344, and Ser425, and similarly to AKT-mediated phosphorylation, these promote the cytoplasmic sequestration of the factor. However, an additional consequence of these modifications is they target the FOXO3A for proteasomal degradation. It has been proposed that this may occur due to increased interaction with the E3-ligase, MDM2 (Yang et al. 2008; see 'Ubiquitination' section).

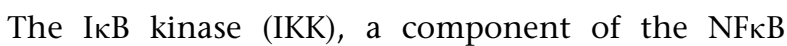
pathway, phosphorylating Ser644, appears to inhibit FOXO3A activity in a similar manner (Hu et al. 2004). This may be of particular relevance to breast tumorigenesis, as constitutive activation of the kinase has been linked to the disease. Furthermore, Chen et al. (2015a)

Published by Bioscientifica Ltd 
Post-translational modifications

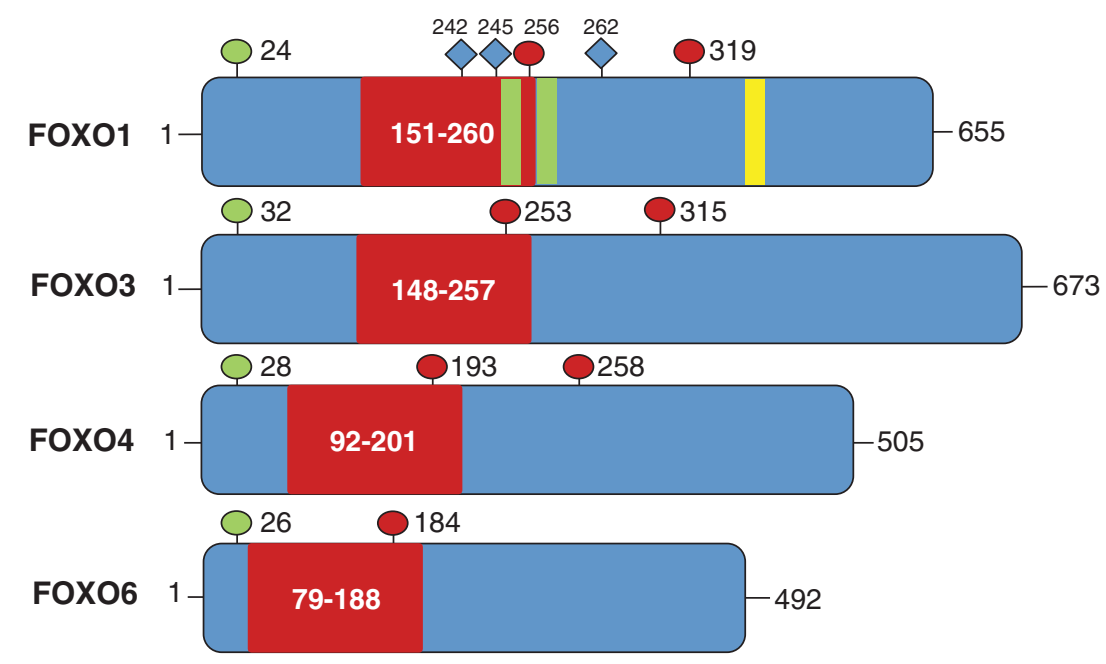

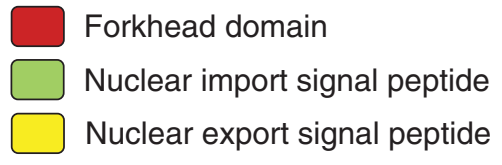

Figure 2

Location of post-translational modifications that regulate FOXO

transcriptional activity. A schematic representation of the four members of

have recently shown that activated-IKK $\beta$ is required to sustain the 'stemness' of breast cancer stem cells.

Casein kinase 1 (CK1) plays a role in cell differentiation and its de-regulation has been shown to contribute to cancer development. CK1 phosphorylates the amino acid residues Ser318 and Ser321 of the FOXO protein, but only following the prior phosphorylation of Ser315 by SGK. In vitro experiments have shown that these phosphorylation events occur in a specific hierarchical fashion: phosphorylation by SGK creates the consensus recognition sequence motif for CK1 phosphorylation $(\mathrm{S} / \mathrm{T}(\mathrm{P}) \mathrm{XXS} / \mathrm{T})$ at Ser318, which in turn creates a second consensus sequence for the CK1 catalysed phosphorylation of Ser321. These modifications are generally believed to influence the rate of nuclear export of FOXOs, potentially through differential interaction with components of the nuclear export complex, though this remains to be proven (Rena et al. 2002).

Dual specificity tyrosine phosphorylated and regulated kinase 1A Dual specificity tyrosine phosphorylated and regulated kinase 1A (DYRK1A), a Ser/Thr kinase, catalyses the phosphorylation of Ser325, in a manner that appears to be independent of SGK-and-CK1 kinase activity, and this the human FOXO family are shown with amino-acid positions of important structural features and modifications highlighted.

acts to induce the nuclear accumulation of FOXOs. DYRK1A mediated modifications also appears to occur independently of PI3K-AKT activity. However, phosphorylation of Ser325 does seem to exhibit a synergistic effect when occurring in concert with SGK-and-CK1mediated phosphorylation. This also may occur as the result of further enhancement of the association of FOXOs with the nuclear export complex; though this also needs to experimentally verified (Gao et al. 2012).

Co-factor interactions The phosphorylation-directed binding of 14-3-3 proteins can also negatively impact the ability of FOXOs to interact with other transcriptional regulatory proteins. FOXOs participate in several known transcriptional complexes, such as: i) ER (Schuur et al. 2001, Zhao et al. 2001); ii) p53 (Wang et al. 2008); and iii) CREB binding protein (CBP)/p300. In the case of $\mathrm{CBP} / \mathrm{p} 300$, the phospho-Thr32/Ser253-isoform has been shown to have lost the ability to physically associate with these transcriptional co-activator proteins (Wang et al. 2009, 2012a), and thus, this modification negates the transcriptionally favorable chromatin remodeling that this protein association generally promotes. $\mathrm{CBP} / \mathrm{p} 300$ also functions to acetylate the lysine residues within the FOX-domain, thus

Published by Bioscientifica Ltd. 
repressing FOXO DNA-binding activity (see 'FOXO acetylation' section).

Activation by kinases There are some reported phosphorylation events that have a positive impact on FOXO activity. For instance, protein kinases such as MST1 (Lehtinen et al. 2006), JNK (Essers et al. 2004), and CDK1 (Yuan et al. 2008), promote nuclear accumulation of FOXOs, generally in response to signals arising from cellular stress (e.g. oxidative stress).

FOXO acetylation The acetylation of FOXOs changes their transcriptional activity. The acetylation-status of a given FOXO is the product of an equilibrium between the action of histone deacetylases (HDACs), such as silent information regulator 1 (SIRT1) and SIRT2; and histone acetyl transferases (HATs), such as CBP/p300 (Daitoku et al. 2011).

Acetylation by HATs deactivates FOXOs through two sequential steps. First, when FOXO are acetylated at three conserved lysine residues (corresponding to Lys242, Lys245, and Lys262 of FOXO1; see Fig. 2), their DNA binding capacity is dramatically reduced (van der Heide \& Smidt 2005, Matsuzaki et al. 2005). Secondly, the acetylated isoform of FOXO has increased potential as an AKT substrate, and it is thus 'sensitized' to PI3K-AKT induced translocation out of the nucleus.

The deacetylation of FOXOs is performed by both class I HDACs and the class III, NAD-dependent histone HDACs (members of the Sirtuin protein family). The effect of SIRT1 activity on the transcription regulatory function of FOXOs varies for different subsets of FOXO-regulated genes. It appears that some FOXO-regulated genes, especially genes related to cell-cycle control and senescence, are up-regulated; while pro-apoptotic genes are down-regulated. For instance, SIRT1-mediated acetylation increases the ability of FOXOs to induce cell-cycle arrest and promote resistance to oxidative stress (e.g. up-regulation of $\mathrm{p} 27^{\mathrm{KIP} 1}$ and GADD45; Daitoku et al. 2004, Kobayashi et al. 2005). In contrast, SIRT1 negatively regulates the FOXO-induced expression of pro-apoptotic genes. Wang et al. (2015), investigating the role of SIRT1 in an in vitro oxidative stress-induced apoptosis model, observed that a decrease in FOXO3A-acetylation accompanied a corresponding increase in ubiquitination (see 'Ubiquitination' section). The subsequent degradation of the protein leads to down-regulation of FOXO3Aregulated pro-apoptotic genes. Also, in an in vitro mouse myoblast oxidative stress model, the expression of FOXO1, FOXO3A, and FOXO4 were all found to be indispensable for anti-apoptotic effects of SIRT1 activity (Hori et al. 2013). The underlying mechanisms responsible for this selective effect of SIRT1 on FOXO3A-regulated genes are not understood.

Other members of SIRT family like SIRT2 and SIRT3 can also interact and deacetylate FOXOs (Jacobs et al. 2008, Sundaresan et al. 2009, Wang et al. 2012b). Also, class I HDAC4/5 has been observed to recruit the deacetylase activity of HDAC3 to FOXO, which results in activation of FOXO-regulated genes (Mihaylova et al. 2011).

Ubiquitination Expression levels of FOXOs are also governed by ubiquitin-regulated proteolysis. The PI3K$\mathrm{AKT}, \mathrm{NF \kappa B}$, and ERK signaling pathways have all been implicated in regulating this process. The E3-ubiquitin ligase S-phase kinase-associated protein 2 (SKP2) is recruited by the AKT-phosphorylated Ser256 of cytoplasmic FOXO1 and proteasomal-mediated degradation of FOXO1 can be rapidly induced in response to PI3K-AKT pathway stimulation (Huang et al. 2005). In contrast, the $\mathrm{NF \kappa B}$ appears to be the relevant signaling pathway for targeting FOXO3A to the proteasome. Hu et al. (2004) found that the IKK $\beta$ mediated phosphorylation of FOXO3A at Ser664, targeted the protein for ubiquitindependent proteolysis; however, as or yet, the ubiquitin responsible remains to be identified.

Another E3-protein ligase MDM2 is activated by ERK-pathway activity, to induce both mono- and polyubiquitination of FOXOs. Interestingly, these two modifications of FOXO have very different effects on their function. The monoubiquitinated isoform of FOXO cannot be acetylated, thus the modification maintains the factor in an in-active, but 'transcriptionally poised' state (van der Horst et al. 2006, Brenkman et al. 2008). It is thought that this form of the protein can be rapidly activated, in response to certain stress stimuli (e.g. oxidative stress), most likely through the action of the deubiquitinating enzyme USP7/herpesvirus-associated ubiquitin-specific protease (van der Horst et al. 2006). In contrast, polyubiquitination targets FOXO proteins for proteasome-mediated degradation, and so, long-term inhibition of FOXO transcriptional activity (Fu et al. 2009). Activation of the PI3K-AKT pathway has been implicated in stimulating FOXO proteolysis in several different cellular contexts (Matsuzaki et al. 2003, Plas \& Thompson 2003, Aoki et al. 2004). In addition to AKT, other kinases such as IKK and ERK have been observed to promote the proteolysis of FOXO3A (Hu et al. 2004, Yang et al. 2008).

Published by Bioscientifica Ltd. 
It has been proposed, that in response to certain cellular conditions (e.g. high expression levels of MDM2), monoubiquitination of FOXO4 can promote its subsequent polyubiquitination by SKP2.

\section{Therapeutics targeting the PI3K-AKT-FOXO signaling axis}

Clinical interventions that are able to restore FOXO tumor suppressor function, could potentially be used as therapeutic strategies to overcome endocrine resistance (Hill et al. 2014a). To this end, potential drug targets that warrant future investigation include: i) growth factor signaling pathways that converge on, and negatively regulate FOXO; ii) the cellular transportation machinery responsible for the nuclear/cytoplasmic shuttling of FOXOs; iii) proteasomes that target FOXOs for degradation; and iv) the DNA-binding activity of the FOXO proteins themselves (see Fig. 3).

\section{PI3K-AKT pathway inhibition}

Preclinical studies As has been described, numerous studies have implicated PI3K-AKT-FOXO dysregulation as possessing a significant contributory role in the development of endocrine resistance. This has spurred the trial of endocrine/PI3K-inhibition combination therapies, and initial pre-clinical studies have generally yielded encouraging results in terms of the potential utility of these strategies to prevent or overcome resistance.
Unfortunately, the examination of FOXO activity was beyond the scope of the majority of these studies; though it is likely that future experiments will demonstrate that FOXOs have a contributory role in many of the positive effects observed.

The simultaneous treatment of $\mathrm{ER}+/ \mathrm{HER} 2+$ breast cancer cells (the BT-474 cell-line) with the anti-HER2 antibody trastuzumab (Herceptin) and tamoxifen, synergistically inhibits their growth in vitro, and also within a xenograft mouse model (Argiris et al. 2004, Wang et al. 2005). Targeting HER2 was found to potently inhibit both the PI3K-AKT and ERK signaling pathway in these experiments. Another pre-clinical study found that treating tamoxifen-resistant breast cancer cells (MCF7 cells expressing constitutively active AKT) with the mTOR inhibitors CCI-779 (temsirolimus) or rapamycin, restored the sensitivity of these cells to tamoxifen-induced growth inhibition (deGraffenried et al. 2004). The mTOR1 complex is a downstream target of PI3K-AKT signaling; directing cellular metabolism and growth, and its dysregulation is frequently implicated in human malignancy (Dibble \& Cantley 2015).

Miller et al. (2010) observed that their in vitro acquired resistance model is heavily reliant on PI3K-AKT-mTOR signaling. They created several long-term estrogen deprivation (LTED) breast cancer cell-lines to study the mechanisms of escape from $\mathrm{E}_{2}$ dependent growth. Molecular characterization of the LTEDs revealed significantly increased AKT and mTOR activity compared with

\section{Potential therapeutic targets of FOXO signaling}

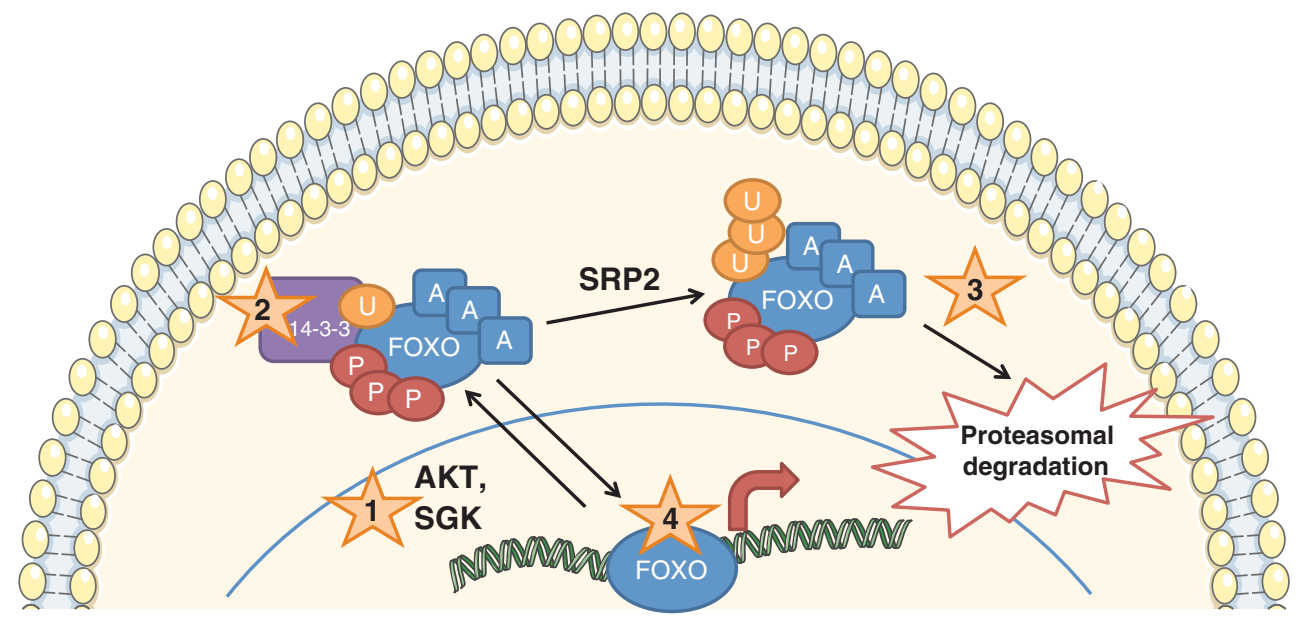

Figure 3

Potential therapeutic targets that could be used to restore FOXO signaling activity in breast cancer cells: (1) kinase signaling pathways that promote nuclear export and sequestration of FOXOs in the cytoplasm; (2) chaperone
(C) 2016 Society for Endocrinology Printed in Great Britain proteins such as 14-3-3 and exportins; (3) proteasomal degradation of FOXOs; and (4) FOXO interaction with DNA-promoter targets and transcriptional machinery. 
the corresponding parental cell-lines. Furthermore, the PI3K/mTOR dual inhibitor, BEZ235, was extremely effective at inducing growth arrest and apoptosis of LTEDs, and also effectively prevented the emergence of new resistant cancer cell populations (Miller et al. 2010). In a subsequent study, Miller et al. (2011) observed an $\mathrm{E}_{2}$-independent ER transcriptional activity; that directs the cell-cycle progression of both LTEDs and primary cultures of AI treated breast tumors. Combined down-regulation of ER (fulvestrant) and PI3K inhibition with BKM120 (Buparlisib) induces a regression of tumors comprising these cells (Miller et al. 2011).

To date, only a small number of studies have directly examined FOXO activity in response to PI3K inhibition within breast cancer cells. Recently, Hill et al. $(2014 a, b)$ reported that the compound ETP-45658, a pyrazolopyrimidine derivative that is a PI3K inhibitor, potently inhibited the growth of breast cancer cells via cell-cycle arrest (observed in MCF7 and MDA-MB231 breast cancer cell-line models). The authors observed treatment of MCF7 cells inhibited and increased phosphorylation (Ser253) and nuclear accumulation of FOXO3A, respectively, and specifically induced a FOXO-dependent transcriptional response enriched for cell-cycle related genes (Hill et al. 2014b). Chu et al. (2015) found that treatment of human breast cancer cells with a 2-aryl benzimidazole compound, that likely targets EGFR and HER2 signaling activity, inhibited the phosphorylation of FOXO1 (Ser319 and Ser256) and FOXO3A (Thr32 and Thr24), promoting the translocation of these FOXO proteins from the cytoplasm into the nucleus.

Although there is little data in the context of breast cancer, restoration of FOXO activity by PI3K-AKT inhibition has also been observed in the treatment of a variety of other human cancers. For instance, treatment of chronic myeloid leukaemia with the pan tyrosine kinase inhibitor imatinib (Gleevec), inhibited PI3K-AKT signaling, and effectively restored FOXO3A transcriptional activity (Fernandez de Mattos et al. 2004, Essafi et al. 2005). A similar effect is also observed in osteosarcoma cells treated with the PI3K-AKT inhibitor Grifolin (Jin et al. 2007).

Clinical trials Clinical trials have also shown the efficacy of PI3K-AKT pathway inhibition as a strategy to overcome endocrine resistance. Two trials have investigated the utility of treating ER +/HER2 + metastatic breast cancers with combination of anastrozole (AI) treatment and HER2 inhibition; with either trastuzumab or latatinib. In both trials, progression-free survival (PFS) was found to be superior in the combination arms (Johnston et al. 2009, Kaufman et al. 2009).

More recently, some large clinical trials have explored whether targeting mTORC1 is of benefit to patients with $\mathrm{ER}+$ breast tumors; that have relapsed following previous AI treatment. In the tamoxifen plus RAD001 phase-II trial, metastatic breast cancer patients were randomized to tamoxifen combined with the mTOR inhibitor everolimus (formerly known as RAD001) or tamoxifen alone (Bachelot et al. 2012). Statistically significant improvements in PFS and clinical benefit were seen in the combination arm (8.6 months vs 4.6 months with tamoxifen alone, hazard ratio (HR) 0.54). Of note, subgroup analysis revealed that the benefit received from combination therapy is only seen in patients with acquired resistance.

In the breast cancer trials of oral everolimus 2 (BOLERO-2) phase-III trial, post-menopausal with ER+ HER2 - advanced breast cancer were randomized to groups receiving everolimus or placebo, combined with the AI exemestane (Baselga et al. 2012, Yardley et al. 2013). The final study results (median follow-up of 18 months) showed that everolimus combined with the AI improves PFS in patients with ER + HER - cancers that had been previously treated with non-steroidal AIs (letrozole or anastrozole). The primary end-point PFS was more than doubled in the combination treatment arm (7.8 months vs 3.2 months in the combination and exemestane alone arms, respectively; HR 0.89; 95\% CI 0.38-0.54; $P<0.0001$; Yardley et al. 2013). Furthermore, subgroup analysis showed that clear improvement in PFS in elderly patients (improved median PFS by 2.82 months in patients $>65$ years of age, HR 0.59 ; and by 5.26 months in patients $\geq 70$ years of age, HR 0.45 ; in the combination and exemestane alone arms respectively), an outcome of particular clinical importance considering the typical age distribution of women with ER + advanced breast cancer (Pritchard et al. 2013).

However, despite being generally well-tolerated, there are still some significant toxicity issues caused by everolimus treatment. Commonly reported symptoms include fatigue, stomatitis, rashes, hyperglycemia, hypolipidemia, myelosuppression, and diarrhea. Also, $3 \%$ of patients have reported non-infectious pneumonia which appears to be immunologically mediated. These are typical class-effects associated with mTOR inhibitors. Fortunately most of these adverse effects are not life-threatening and can be managed by proper prevention and management strategies (reviewed by Rugo (2015)).

These data are generally encouraging that strategies that employ simultaneous targeting of PI3K-AKT and ER

Published by Bioscientifica Ltd. 
pathways may be of benefit to breast cancer patients with acquired resistance. Indeed, on the basis of the BOLERO-2 study, FDA approval was granted for the use of everolimus in combination with exemestane for the treatment of ER+ HER - advanced breast cancer that have progressed during treatment with either letrozole or anastrozole. However, since then, analysis of the overall survival data has revealed that for this secondary end-point of the study, there was no significant difference between the treatment arms (Piccart et al. 2014). This lack of a robust clinical response could be, as is often the case for PI3K-AKT targeting therapeutics, the result of cellular resistance mechanisms to PI3K-AKT inhibition.

\section{Resistance mechanisms to PI3K-AKT inhibi-}

tion Both clinical and pre-clinical studies have identified several different mechanisms by which resistance to PI3K-AKT-mTOR inhibition can arise. These include feedback activation of AKT, increased expression of RTKs and cross-talk with other growth-promoting pathways (reviewed in detail by Thorpe et al. (2015)).

Of particular relevance to the subject of this review, restored FOXO activity, following AKT inhibition, directly mediates the up-regulation of HER3, IGF1R, and insulin RTK gene expression (Chandarlapaty et al. 2011).

Recently, Bihani et al. (2015), investigated the mechanisms of acquired resistance of breast cancer cells to everolimus. The authors demonstrated that breast cancer cell-lines, having acquired everolimus resistance, exhibit bromo domain containing protein 4 (BRD4)mediated up-regulation of the $M Y C$ gene. Up-regulation of MYC expression in ER + antiestrogen resistance breast cancer cells triggers a pro-survival autophagic adaptation in glucose deprived culture conditions (Shajahan-Haq et al. 2014). As has already been discussed, autophagy appears to be a central player in mechanisms of endocrine resistance. Promisingly, it is possible to pharmacologically inhibit BRD4, and doing so has been shown to overcome the resistance of the cancer cells to mTOR1 inhibition (Bihani et al. 2015).

Concerning the feedback activation of AKT, the Src/ c-Abl, multikinase-inhibitor dasatinib, has been shown to effectively block AKT activation following mTOR inhibition in several breast cancer cell lines (Yori et al. 2014). Furthermore, the combination treatment of dasatinib and rapamycin has a synergistic effect upon tumor regression in mouse models, accompanied by a reduction in pulmonary metastasis as well as an increase in time to tumor recurrence (Yori et al. 2014).
Other potential therapeutic targets Although the targeting of PI3K-AKT still presents the most promising strategy to restore FOXO activity, acquired resistance to PI3K-AKT inhibition currently presents a significant barrier that needs to be overcome. The current trend of trialling combination therapies, whereby PI3K-AKT is inhibited in conjunction with additional molecular targets, may prove effective in maximizing the clinical efficacy of the PI3K inhibitors. Fortunately, the complex cellular regulation of FOXO factors summarized in this review, presents a number of additional molecular targets that could be potentially investigated.

\section{Nuclear export machinery}

Nuclear export of FOXOs can be blocked by inhibitors of the 14-3-3 chaperone protein family and related exportins. Dong et al. (2007) demonstrated that treatment of an in vitro leukemia cell-model with the peptide R18, downregulated 14-3-3 protein expression, which in turn leads to increased nuclear accumulation of FOXO3A; and restored transcription of its anti-proliferative targets $\mathrm{p} 27^{\mathrm{kip} 1}$ and Bim. More recently, Mori et al. (2014) have developed novel compounds that also interact and inhibit the 14-3-3 chaperone proteins, increasing the possibility that eventually some compounds may be suitable for clinical use.

\section{Proteasome}

Inhibiting the proteasome-mediated degradation of FOXOs could represent an interesting strategy to restore their cellular levels. However, to date, there are no studies on this topic available in the literature.

\section{FOXOs}

Transcription factors are predominantly located in the nucleus and they do not possess enzymatic activity. For these reasons they have historically been considered to be 'undruggable' molecular targets. However, a growing number of studies have challenged this assumption. Improved understanding of transcription factor biology, coupled with improved drug design and delivery, make transcription factors attractive and realistic alternative drug targets. This may be particularly useful in clinical scenarios where targeting kinase signaling pathways in cancer cells have met with limited efficacy (Rodon et al. 2013).

Although no examples of directly targeting FOXOs exist, attempts at targeting other members of the FOX family have been reported. Notably, Bhat et al. (2009)

Published by Bioscientifica Ltd. 
identified two thiazole antibiotic compounds, siomycin-A and thiostrepton, that selectively bind to and inhibit the transcriptional activity of the oncogenic FOXM1 protein in in vitro cancer cell-line models. Although the poor water solubility of these compounds (Zhang \& Kelly 2012) make them of limited clinical use; nevertheless these observations have propelled a search for other small molecule inhibitors of FOXM1 that can be used safely (Chen et al. 2015b).

\section{A need for caution}

It is important to consider that FOXOs are regulators of cellular stress resistance mechanisms, and in at least some circumstances, such treatments may also increase resistance to chemotherapeutics. Therefore, it is crucial to fully characterize FOXO-regulated transcriptional programmes in specific disease-states; to identify those which would be most suitable for targeted reactivation of FOXO tumor suppressor function.

\section{Conclusion}

In conclusion, the dysregulation of FOXO factors has emerged as a key molecular feature of endocrine resistance mechanisms. Both pre-clinical and clinical research has shown the promising potential of targeting the PI3K-AKT pathway; as a therapeutic strategy to restore hormonesensitivity to resistant breast tumors. Furthermore, restoration of FOXO tumor suppressor appears to be a key player in this process. However, PI3K-AKT inhibition may not turn out to be the best approach. As has been discussed, cancer cells can utilize a multitude of different resistance mechanisms to acquire resistance to PI3K-AKT inhibition. Although, preclinical experiments show promising data with regard to blocking PI3K-AKT resistance pathways, it remains to be ascertained whether such strategies will translate into superior clinical efficacy. Therefore, one of the aims of this review was to provide a generalized overview of the multiple interconnected regulatory layers that impact upon FOXO transcriptional activity. Further understanding these processes may identify future molecular targets that can allow clinicians to manipulate FOXOs in a more therapeutically targeted manner.

\section{Declaration of interest}

The author declares that there is no conflict of interest that could be perceived as prejudicing the impartiality of this review.

\section{Funding}

The author is supported by an NHMRC project grant.

\section{Acknowledgements}

The author thanks Associate Professor Rory Clifton-Bligh (Kolling Institute of Medical Research, Royal North Shore Hospital) for helpful discussions.

\section{References}

Adachi M, Osawa Y, Uchinami H, Kitamura T, Accili D \& Brenner DA 2007 The forkhead transcription factor FoxO1 regulates proliferation and transdifferentiation of hepatic stellate cells. Gastroenterology 132 1434-1446. (doi:10.1053/j.gastro.2007.01.033)

Aoki M, Jiang H \& Vogt PK 2004 Proteasomal degradation of the FoxO1 transcriptional regulator in cells transformed by the P3k and Akt oncoproteins. PNAS 101 13613-13617. (doi:10.1073/pnas.0405454101)

Arendt LM \& Kuperwasser C 2015 Form and function: how estrogen and progesterone regulate the mammary epithelial hierarchy. Journal of Mammary Gland Biology and Neoplasia 20 9-25. (doi:10.1007/s10911015-9337-0)

Argiris A, Wang CX, Whalen SG \& DiGiovanna MP 2004 Synergistic interactions between tamoxifen and trastuzumab (Herceptin). Clinical Cancer Research 10 1409-1420. (doi:10.1158/1078-0432.CCR-1060-02)

Arpino G, Green SJ, Allred DC, Lew D, Martino S, Osborne CK \& Elledge RM 2004 HER-2, amplification, HER-1 expression, and tamoxifen response in estrogen receptor-positive metastatic breast cancer: a Southwest Oncology Group Study. Clinical Cancer Research 10 5670-5676. (doi:10.1158/1078-0432.CCR-04-0110)

Bachelot T, Bourgier C, Cropet C, Ray-Coquard I, Ferrero JM, Freyer G, Abadie-Lacourtoisie S, Eymard JC, Debled M, Spaeth D et al. 2012 Randomized phase II trial of everolimus in combination with tamoxifen in patients with hormone receptor-positive, human epidermal growth factor receptor 2-negative metastatic breast cancer with prior exposure to aromatase inhibitors: a GINECO study. Journal of Clinical Oncology 30 2718-2724. (doi:10.1200/JCO.2011.39.0708)

Banerji S, Cibulskis K, Rangel-Escareno C, Brown KK, Carter SL, Frederick AM, Lawrence MS, Sivachenko AY, Sougnez C, Zou L et al. 2012 Sequence analysis of mutations and translocations across breast cancer subtypes. Nature 486 405-409. (doi:10.1038/nature11154)

Baselga J, Campone M, Piccart M, Burris HA III, Rugo HS, Sahmoud T, Noguchi S, Gnant M, Pritchard KI, Lebrun F et al. 2012 Everolimus in postmenopausal hormone-receptor-positive advanced breast cancer. New England Journal of Medicine 366 520-529. (doi:10.1056/ NEJMoa1109653)

Bergamaschi A, Kim YH, Wang P, Sorlie T, Hernandez-Boussard T, Lonning PE, Tibshirani R, Borresen-Dale AL \& Pollack JR 2006 Distinct patterns of DNA copy number alteration are associated with different clinicopathological features and gene-expression subtypes of breast cancer. Genes, Chromosomes \& Cancer 45 1033-1040. (doi:10.1002/gcc.20366)

Bhat UG, Halasi M \& Gartel AL 2009 Thiazole antibiotics target FoxM1 and induce apoptosis in human cancer cells. PLOS ONE 4 e5592. (doi:10.1371/journal.pone.0005592)

Bihani T, Ezell SA, Ladd B, Grosskurth SE, Mazzola AM, Pietras M, Reimer C, Zinda M, Fawell S \& D'Cruz CM 2015 Resistance to everolimus driven by epigenetic regulation of MYC in ER + breast cancers. Oncotarget 6 2407-2420. (doi:10.18632/oncotarget.2964)

Blanco G, Holli K, Heikkinen M, Kallioniemi OP \& Taskinen P 1990 Prognostic factors in recurrent breast cancer: relationships to site of recurrence, disease-free interval, female sex steroid receptors, ploidy and histological malignancy grading. British Journal of Cancer 62 142-146. (doi:10.1038/bjc.1990.247)

Bliss JM, Kilburn LS, Coleman RE, Forbes JF, Coates AS, Jones SE, Jassem J, Delozier T, Andersen J, Paridaens R et al. 2012 Disease-related outcomes with long-term follow-up: an updated analysis of the intergroup

Published by Bioscientifica Ltd 
exemestane study. Journal of Clinical Oncology 30 709-717. (doi:10.1200/JCO.2010.33.7899)

Borgquist S, Holm C, Stendahl M, Anagnostaki L, Landberg G \& Jirstrom K 2008 Oestrogen receptors $\alpha$ and $\beta$ show different associations to clinicopathological parameters and their co-expression might predict a better response to endocrine treatment in breast cancer. Journal of Clinical Pathology 61 197-203. (doi:10.1136/jcp.2006.040378)

Brenkman AB, de Keizer PL, van den Broek NJ, Jochemsen AG \& Burgering BM $2008 \mathrm{Mdm} 2$ induces mono-ubiquitination of FOXO4. PLOS ONE 3 e2819. (doi:10.1371/journal.pone.0002819)

Brisken C 2013 Progesterone signalling in breast cancer: a neglected hormone coming into the limelight. Nature Reviews Cancer 13 385-396. (doi:10.1038/nrc3518)

Brunet A, Bonni A, Zigmond MJ, Lin MZ, Juo P, Hu LS, Anderson MJ, Arden KC, Blenis J \& Greenberg ME 1999 Akt promotes cell survival by phosphorylating and inhibiting a forkhead transcription factor. Cell 96 857-868. (doi:10.1016/S0092-8674(00)80595-4)

Brunet A, Park J, Tran H, Hu LS, Hemmings BA \& Greenberg ME 2001 Protein kinase SGK mediates survival signals by phosphorylating the forkhead transcription factor FKHRL1 (FOXO3a). Molecular and Cellular Biology 21 952-965. (doi:10.1128/MCB.21.3.952-965.2001)

Brunet A, Kanai F, Stehn J, Xu J, Sarbassova D, Frangioni JV, Dalal SN, DeCaprio JA, Greenberg ME \& Yaffe MB 2002 14-3-3 Transits to the nucleus and participates in dynamic nucleocytoplasmic transport. Journal of Cell Biology 156 817-828. (doi:10.1083/jcb.200112059)

Bunone G, Briand PA, Miksicek RJ \& Picard D 1996 Activation of the unliganded estrogen receptor by EGF involves the MAP kinase pathway and direct phosphorylation. EMBO Journal 15 2174-2183.

Burns KA \& Korach KS 2012 Estrogen receptors and human disease: an update. Archives of Toxicology 86 1491-1504. (doi:10.1007/s00204-0120868-5)

Cancer Genome Atlas N 2012 Comprehensive molecular portraits of human breast tumours. Nature 490 61-70. (doi:10.1038/nature11412)

Castrillon DH, Miao L, Kollipara R, Horner JW \& DePinho RA 2003 Suppression of ovarian follicle activation in mice by the transcription factor Foxo3a. Science 301 215-218. (doi:10.1126/science.1086336)

Chandarlapaty S, Sawai A, Scaltriti M, Rodrik-Outmezguine V, GrbovicHuezo O, Serra V, Majumder PK, Baselga J \& Rosen N 2011 AKT inhibition relieves feedback suppression of receptor tyrosine kinase expression and activity. Cancer Cell 19 58-71. (doi:10.1016/j.ccr.2010. 10.031)

Chen C, Cao F, Bai L, Liu Y, Xie J, Wang W, Si Q, Yang J, Chang A, Liu D et al. 2015 a IKK $\beta$ enforces a LIN28B/TCF7L2 positive feedback loop that promotes cancer cell stemness and metastasis. Cancer Research $\mathbf{7 5}$ 1725-1735. (doi:10.1158/0008-5472.CAN-14-2111)

Chen Y, Ruben EA, Rajadas J \& Teng NN 2015b In silico investigation of FOXM1 binding and novel inhibitors in epithelial ovarian cancer. Bioorganic \& Medicinal Chemistry 23 4576-4782. (doi:10.1016/j.bmc. 2015.06.002)

Chin K, DeVries S, Fridlyand J, Spellman PT, Roydasgupta R, Kuo WL, Lapuk A, Neve RM, Qian Z, Ryder T et al. 2006 Genomic and transcriptional aberrations linked to breast cancer pathophysiologies. Cancer Cell 10 529-541. (doi:10.1016/j.ccr.2006.10.009)

Chu B, Liu F, Li L, Ding C, Chen K, Sun Q, Shen Z, Tan Y, Tan C \& Jiang Y 2015 A benzimidazole derivative exhibiting antitumor activity blocks EGFR and HER2 activity and upregulates DR5 in breast cancer cells. Cell Death \& Disease 6 e1686. (doi:10.1038/cddis.2015.25)

Clarke R \& Cook KL 2015 Unfolding the role of stress response signaling in endocrine resistant breast cancers. Frontiers in Oncology 5140. (doi:10.3389/fonc.2015.00140)

Conneely OM, Mulac-Jericevic B \& Arnett-Mansfield R 2007 Progesterone signaling in mammary gland development. Ernst Schering Foundation Symposium Proceedings 1 45-54. (doi:10.1007/2789_2008_075)

Cook KL, Shajahan AN, Warri A, Jin L, Hilakivi-Clarke LA \& Clarke R 2012 Glucose-regulated protein 78 controls cross-talk between apoptosis and autophagy to determine antiestrogen responsiveness. Cancer Research 72 3337-3349. (doi:10.1158/0008-5472.CAN-12-0269)

Cook KL, Clarke PA, Parmar J, Hu R, Schwartz-Roberts JL, Abu-Asab M, Warri A, Baumann WT \& Clarke R 2014 Knockdown of estrogen receptor- $\alpha$ induces autophagy and inhibits antiestrogen-mediated unfolded protein response activation, promoting ROS-induced breast cancer cell death. FASEB Journal 28 3891-3905. (doi:10.1096/ fj.13-247353)

Daitoku H, Hatta M, Matsuzaki H, Aratani S, Ohshima T, Miyagishi M, Nakajima T \& Fukamizu A 2004 Silent information regulator 2 potentiates Foxo1-mediated transcription through its deacetylase activity. PNAS 101 10042-10047. (doi:10.1073/pnas.0400593101)

Daitoku H, Sakamaki J \& Fukamizu A 2011 Regulation of FoxO transcription factors by acetylation and protein-protein interactions. Biochimica et Biophysica Acta 1813 1954-1960. (doi:10.1016/j.bbamcr. 2011.03.001)

De Laurentiis M, Arpino G, Massarelli E, Ruggiero A, Carlomagno C, Ciardiello F, Tortora G, D'Agostino D, Caputo F, Cancello G et al. 2005 A meta-analysis on the interaction between HER-2 expression and response to endocrine treatment in advanced breast cancer. Clinical Cancer Research 11 4741-4748. (doi:10.1158/1078-0432.CCR-04-2569)

Deroo BJ, Hewitt SC, Collins JB, Grissom SF, Hamilton KJ \& Korach KS 2009 Profile of estrogen-responsive genes in an estrogen-specific mammary gland outgrowth model. Molecular Reproduction and Development 76 733-750. (doi:10.1002/mrd.21041)

Dibble CC \& Cantley LC 2015 Regulation of mTORC1 by PI3K signaling. Trends in Cell Biology 25 545-555. (doi:10.1016/j.tcb.2015.06.002)

Dijkers PF, Medema RH, Pals C, Banerji L, Thomas NS, Lam EW, Burgering BM, Raaijmakers JA, Lammers JW, Koenderman L et al. 2000 Forkhead transcription factor FKHR-L1 modulates cytokine-dependent transcriptional regulation of p27(KIP1). Molecular and Cellular Biology 20 9138-9148. (doi:10.1128/MCB.20.24.9138-9148.2000)

Dong S, Kang S, Gu TL, Kardar S, Fu H, Lonial S, Khoury HJ, Khuri F \& Chen J 2007 14-3-3 Integrates prosurvival signals mediated by the AKT and MAPK pathways in ZNF198-FGFR1-transformed hematopoietic cells. Blood 110 360-369. (doi:10.1182/blood-2006-12-065615)

Eijkelenboom A, Mokry M, de Wit E, Smits LM, Polderman PE, van Triest MH, van Boxtel R, Schulze A, de Laat W, Cuppen E et al. 2013 Genome-wide analysis of FOXO3 mediated transcription regulation through RNA polymerase II profiling. Molecular Systems Biology 9638. (doi:10.1038/msb.2012.74)

Essafi A, Fernandez de Mattos S, Hassen YA, Soeiro I, Mufti GJ, Thomas NS, Medema RH \& Lam EW 2005 Direct transcriptional regulation of Bim by FoxO3a mediates STI571-induced apoptosis in Bcr-Abl-expressing cells. Oncogene 24 2317-2329. (doi:10.1038/sj.onc.1208421)

Essers MA, Weijzen S, de Vries-Smits AM, Saarloos I, de Ruiter ND, Bos JL \& Burgering BM 2004 FOXO transcription factor activation by oxidative stress mediated by the small GTPase Ral and JNK. EMBO Journal 23 4802-4812. (doi:10.1038/sj.emboj.7600476)

Fan W, Morinaga H, Kim JJ, Bae E, Spann NJ, Heinz S, Glass CK \& Olefsky JM 2010 FoxO1 regulates Tlr4 inflammatory pathway signalling in macrophages. EMBO Journal 29 4223-4236. (doi:10.1038/ emboj.2010.268)

Fernandez de Mattos S, Essafi A, Soeiro I, Pietersen AM, Birkenkamp KU, Edwards CS, Martino A, Nelson BH, Francis JM, Jones MC et al. 2004 FoxO3a and BCR-ABL regulate cyclin D2 transcription through a STAT5/BCL6-dependent mechanism. Molecular and Cellular Biology 24 10058-10071. (doi:10.1128/MCB.24.22.10058-10071.2004)

Fox EM, Miller TW, Balko JM, Kuba MG, Sanchez V, Smith RA, Liu S, Gonzalez-Angulo AM, Mills GB, Ye F et al. 2011 A kinome-wide screen identifies the insulin/IGF-I receptor pathway as a mechanism of escape from hormone dependence in breast cancer. Cancer Research $\mathbf{7 1}$ 6773-6784. (doi:10.1158/0008-5472.CAN-11-1295)

Frogne T, Benjaminsen RV, Sonne-Hansen K, Sorensen BS, Nexo E, Laenkholm AV, Rasmussen LM, Riese DJ II, de Cremoux P, Stenvang J et al. 2009 Activation of ErbB3, EGFR and Erk is essential for growth of 
human breast cancer cell lines with acquired resistance to fulvestrant. Breast Cancer Research and Treatment 114 263-275. (doi:10.1007/ s10549-008-0011-8)

Fruman DA \& Rommel C 2014 PI3K and cancer: lessons, challenges and opportunities. Nature Reviews. Drug Discovery 13 140-156. (doi:10.1038/ nrd4204)

Fu W, Ma Q, Chen L, Li P, Zhang M, Ramamoorthy S, Nawaz Z, Shimojima T, Wang H, Yang Y et al. 2009 MDM2 acts downstream of p53 as an E3 ligase to promote FOXO ubiquitination and degradation. Journal of Biological Chemistry 284 13987-14000. (doi:10.1074/jbc.M901758200)

Furuyama T, Nakazawa T, Nakano I \& Mori N 2000 Identification of the differential distribution patterns of mRNAs and consensus binding sequences for mouse DAF-16 homologues. Biochemical Journal 349 629-634. (doi:10.1042/bj3490629)

Gajiwala KS \& Burley SK 2000 Winged helix proteins. Current Opinion in Structural Biology 10 110-116. (doi:10.1016/S0959-440X(99)00057-3)

Galili N, Davis RJ, Fredericks WJ, Mukhopadhyay S, Rauscher FJ III, Emanuel BS, Rovera G \& Barr FG 1993 Fusion of a fork head domain gene to PAX3 in the solid tumour alveolar rhabdomyosarcoma. Nature Genetics 5 230-235. (doi:10.1038/ng1193-230)

Gao J, Yang X, Yin P, Hu W, Liao H, Miao Z, Pan C \& Li N 2012 The involvement of FoxO in cell survival and chemosensitivity mediated by Mirk/Dyrk1B in ovarian cancer. International Journal of Oncology $\mathbf{4 0}$ 1203-1209. (doi:10.3892/ijo.2011.1293)

Gargini R, Cerliani JP, Escoll M, Anton IM \& Wandosell F 2015 Cancer stem cell-like phenotype and survival are coordinately regulated by Akt/FoxO/Bim pathway. Stem Cells 33 646-660. (doi:10.1002/stem.1904)

deGraffenried LA, Friedrichs WE, Russell DH, Donzis EJ, Middleton AK, Silva JM, Roth RA \& Hidalgo M 2004 Inhibition of mTOR activity restores tamoxifen response in breast cancer cells with aberrant Akt Activity. Clinical Cancer Research 10 8059-8067. (doi:10.1158/ 1078-0432.CCR-04-0035)

Halacli SO \& Dogan AL 2015 FOXP1 regulation via the PI3K/Akt/p70S6K signaling pathway in breast cancer cells. Oncology Letters 9 1482-1488. (doi:10.3892/ol.2015.2885)

van der Heide LP \& Smidt MP 2005 Regulation of FoxO activity by CBP/p300-mediated acetylation. Trends in Biochemical Sciences 30 81-86. (doi:10.1016/j.tibs.2004.12.002)

Hill R, Cautain B, de Pedro N \& Link W 2014a Targeting nucleocytoplasmic transport in cancer therapy. Oncotarget 5 11-28. (doi:10.18632/ oncotarget.1457)

Hill R, Kalathur RK, Callejas S, Colaco L, Brandao R, Serelde B, Cebria A, Blanco-Aparicio C, Pastor J, Futschik M et al. 2014b A novel phosphatidylinositol 3-kinase (PI3K) inhibitor directs a potent FOXOdependent, p53-independent cell cycle arrest phenotype characterized by the differential induction of a subset of FOXO-regulated genes. Breast Cancer Research 16 482. (doi:10.1186/s13058-014-0482-y)

Hori YS, Kuno A, Hosoda R \& Horio Y 2013 Regulation of FOXOs and p53 by SIRT1 modulators under oxidative stress. PLOS ONE $\mathbf{8}$ e73875. (doi:10.1371/journal.pone.0073875)

van der Horst A, de Vries-Smits AM, Brenkman AB, van Triest MH, van den Broek N, Colland F, Maurice MM \& Burgering BM 2006 FOXO4 transcriptional activity is regulated by monoubiquitination and USP7/HAUSP. Nature Cell Biology 8 1064-1073. (doi:10.1038/ncb1469)

Hosaka T, Biggs WH III, Tieu D, Boyer AD, Varki NM, Cavenee WK \& Arden KC 2004 Disruption of forkhead transcription factor (FOXO) family members in mice reveals their functional diversification. PNAS 101 2975-2980. (doi:10.1073/pnas.0400093101)

Hu MC, Lee DF, Xia W, Golfman LS, Ou-Yang F, Yang JY, Zou Y, Bao S, Hanada N, Saso H et al. 2004 IкB kinase promotes tumorigenesis through inhibition of forkhead FOXO3a. Cell 117 225-237. (doi:10.1016/S0092-8674(04)00302-2)

Huang H, Regan KM, Wang F, Wang D, Smith DI, van Deursen JM \& Tindall DJ 2005 Skp2 inhibits FOXO1 in tumor suppression through ubiquitin-mediated degradation. PNAS 102 1649-1654. (doi:10.1073/ pnas.0406789102)

Imae M, Fu Z, Yoshida A, Noguchi T \& Kato H 2003 Nutritional and hormonal factors control the gene expression of FoxOs, the mammalian homologues of DAF-16. Journal of Molecular Endocrinology 30 253-262. (doi:10.1677/jme.0.0300253)

Jacobs FM, van der Heide LP, Wijchers PJ, Burbach JP, Hoekman MF \& Smidt MP 2003 FoxO6, a novel member of the FoxO class of transcription factors with distinct shuttling dynamics. Journal of Biological Chemistry 278 35959-35967. (doi:10.1074/jbc.M302804200)

Jacobs KM, Pennington JD, Bisht KS, Aykin-Burns N, Kim HS, Mishra M, Sun L, Nguyen P, Ahn BH, Leclerc J et al. 2008 SIRT3 interacts with the daf-16 homolog FOXO3a in the mitochondria, as well as increases FOXO3a dependent gene expression. International Journal of Biological Sciences 4 291-299. (doi:10.7150/ijbs.4.291)

Jacobsen BM \& Horwitz KB 2012 Progesterone receptors, their isoforms and progesterone regulated transcription. Molecular and Cellular Endocrinology 357 18-29. (doi:10.1016/j.mce.2011.09.016)

Jia M, Dahlman-Wright K \& Gustafsson JA 2015 Estrogen receptor $\alpha$ and $\beta$ in health and disease. Best Practice \& Research. Clinical Endocrinology \& Metabolism 29 557-568. (doi:10.1016/j.beem.2015.04.008)

Jin S, Pang RP, Shen JN, Huang G, Wang J \& Zhou JG 2007 Grifolin induces apoptosis via inhibition of PI3K/AKT signalling pathway in human osteosarcoma cells. Apoptosis 12 1317-1326. (doi:10.1007/s10495-0070062-z)

Johnston S, Pippen J Jr, Pivot X, Lichinitser M, Sadeghi S, Dieras V, Gomez HL, Romieu G, Manikhas A, Kennedy MJ et al. 2009 Lapatinib combined with letrozole versus letrozole and placebo as first-line therapy for postmenopausal hormone receptor-positive metastatic breast cancer. Journal of Clinical Oncology 27 5538-5546. (doi:10.1200/ JCO.2009.23.3734)

Kato S, Endoh H, Masuhiro Y, Kitamoto T, Uchiyama S, Sasaki H, Masushige S, Gotoh Y, Nishida E, Kawashima H et al. 1995 Activation of the estrogen receptor through phosphorylation by mitogen-activated protein kinase. Science 270 1491-1494. (doi:10.1126/science.270.5241. 1491)

Katoh M \& Katoh M 2004 Human FOX gene family (review). International Journal of Oncology 25 1495-1500. (doi:10.3892/ijo.25.5.1495)

Kaufman B, Mackey JR, Clemens MR, Bapsy PP, Vaid A, Wardley A, Tjulandin S, Jahn M, Lehle M, Feyereislova A et al. 2009 Trastuzumab plus anastrozole versus anastrozole alone for the treatment of postmenopausal women with human epidermal growth factor receptor 2-positive, hormone receptor-positive metastatic breast cancer: results from the randomized phase III TAnDEM study. Journal of Clinical Oncology 27 5529-5537. (doi:10.1200/JCO.2008.20.6847)

Kirkegaard T, Witton CJ, Edwards J, Nielsen KV, Jensen LB, Campbell FM, Cooke TG \& Bartlett JM 2010 Molecular alterations in AKT1, AKT2 and AKT3 detected in breast and prostatic cancer by FISH. Histopathology $\mathbf{5 6}$ 203-211. (doi:10.1111/j.1365-2559.2009.03467.x)

Kobayashi Y, Furukawa-Hibi Y, Chen C, Horio Y, Isobe K, Ikeda K \& Motoyama N 2005 SIRT1 is critical regulator of FOXO-mediated transcription in response to oxidative stress. International Journal of Molecular Medicine 16 237-243. (doi:10.3892/ijmm.16.2.237)

Lagutina I, Conway SJ, Sublett J \& Grosveld GC 2002 Pax3-FKHR knock-in mice show developmental aberrations but do not develop tumors. Molecular and Cellular Biology 22 7204-7216. (doi:10.1128/MCB.22.20. 7204-7216.2002)

Lalmansingh AS, Karmakar S, Jin Y \& Nagaich AK 2012 Multiple modes of chromatin remodeling by forkhead box proteins. Biochimica et Biophysica Acta 1819 707-715. (doi:10.1016/j.bbagrm.2012.02.018)

Lam EW, Francis RE \& Petkovic M 2006 FOXO transcription factors: key regulators of cell fate. Biochemical Society Transactions 34 722-726. (doi:10.1042/BST0340722)

Laoukili J, Stahl M \& Medema RH 2007 FoxM1: at the crossroads of ageing and cancer. Biochimica et Biophysica Acta 1775 92-102. (doi:10.1016/j. bbcan.2006.08.006) 
Lavinsky RM, Jepsen K, Heinzel T, Torchia J, Mullen TM, Schiff R, Del-Rio AL, Ricote M, Ngo S, Gemsch J et al. 1998 Diverse signaling pathways modulate nuclear receptor recruitment of N-CoR and SMRT complexes. PNAS 95 2920-2925. (doi:10.1073/pnas.95.6.2920)

Lee YR, Park J, Yu HN, Kim JS, Youn HJ \& Jung SH 2005 Up-regulation of PI3K/Akt signaling by $17 \beta$-estradiol through activation of estrogen receptor- $\alpha$, but not estrogen receptor- $\beta$, and stimulates cell growth in breast cancer cells. Biochemical and Biophysical Research Communications 336 1221-1226. (doi:10.1016/j.bbrc.2005.08.256)

Lehtinen MK, Yuan Z, Boag PR, Yang Y, Villen J, Becker EB, DiBacco S, de la Iglesia N, Gygi S, Blackwell TK et al. 2006 A conserved MST-FOXO signaling pathway mediates oxidative-stress responses and extends life span. Cell 125 987-1001. (doi:10.1016/j.cell.2006.03.046)

Li S, Han B, Liu G, Li S, Ouellet J, Labrie F \& Pelletier G 2010 Immunocytochemical localization of sex steroid hormone receptors in normal human mammary gland. Journal of Histochemistry and Cytochemistry 58 509-515. (doi:10.1369/jhc.2009.954644)

Lin YC, Jhunjhunwala S, Benner C, Heinz S, Welinder E, Mansson R, Sigvardsson M, Hagman J, Espinoza CA, Dutkowski J et al. 2010 A global network of transcription factors, involving E2A, EBF1 and Foxo1, that orchestrates B cell fate. Nature Immunology 11 635-643. (doi:10.1038/ni.1891)

Litvak V, Ratushny AV, Lampano AE, Schmitz F, Huang AC, Raman A, Rust AG, Bergthaler A, Aitchison JD \& Aderem A 2012 A FOXO3-IRF7 gene regulatory circuit limits inflammatory sequelae of antiviral responses. Nature 490 421-425. (doi:10.1038/nature11428)

Lv Y, Song S, Zhang K, Gao H \& Ma R 2013 CHIP regulates AKT/FoxO/Bim signaling in MCF7 and MCF10A cells. PLOS ONE 8 e83312. (doi:10.1371/journal.pone.0083312)

Martini M, De Santis MC, Braccini L, Gulluni F \& Hirsch E 2014 PI3K/AKT signaling pathway and cancer: an updated review. Annals of Medicine 46 372-383. (doi:10.3109/07853890.2014.912836)

Matsuzaki H, Daitoku H, Hatta M, Tanaka K \& Fukamizu A 2003 Insulininduced phosphorylation of FKHR (Foxo1) targets to proteasomal degradation. PNAS 100 11285-11290. (doi:10.1073/pnas.1934283100)

Matsuzaki H, Daitoku H, Hatta M, Aoyama H, Yoshimochi K \& Fukamizu A 2005 Acetylation of Foxo1 alters its DNA-binding ability and sensitivity to phosphorylation. PNAS 102 11278-11283. (doi:10.1073/pnas. 0502738102)

McClaine RJ, Marshall AM, Wagh PK \& Waltz SE 2010 Ron receptor tyrosine kinase activation confers resistance to tamoxifen in breast cancer cell lines. Neoplasia 12 650-658. (doi:10.1593/neo.10476)

Mihaylova MM, Vasquez DS, Ravnskjaer K, Denechaud PD, Yu RT, Alvarez JG, Downes M, Evans RM, Montminy M \& Shaw RJ 2011 Class IIa histone deacetylases are hormone-activated regulators of FOXO and mammalian glucose homeostasis. Cell 145 607-621. (doi:10.1016/j. cell.2011.03.043)

Miller TW, Hennessy BT, Gonzalez-Angulo AM, Fox EM, Mills GB, Chen H, Higham C, Garcia-Echeverria C, Shyr Y \& Arteaga CL 2010 Hyperactivation of phosphatidylinositol-3 kinase promotes escape from hormone dependence in estrogen receptor-positive human breast cancer. Journal of Clinical Investigation 120 2406-2413. (doi:10.1172/ JCI41680)

Miller TW, Balko JM, Fox EM, Ghazoui Z, Dunbier A, Anderson H, Dowsett M, Jiang A, Smith RA, Maira SM et al. 2011 ER $\alpha$-dependent E2F transcription can mediate resistance to estrogen deprivation in human breast cancer. Cancer Discovery 1 338-351. (doi:10.1158/2159-8290.CD11-0101)

Modur V, Nagarajan R, Evers BM \& Milbrandt J 2002 FOXO proteins regulate tumor necrosis factor-related apoptosis inducing ligand expression. Implications for PTEN mutation in prostate cancer. Journal of Biological Chemistry 277 47928-47937. (doi:10.1074/jbc. M207509200)

Montenegro MF, Collado-Gonzalez Mdel M, Fernandez-Perez MP, Hammouda MB, Tolordava L, Gamkrelidze M \& Rodriguez-Lopez JN 2014 Promoting E2F1-mediated apoptosis in oestrogen receptor- $\alpha$-negative breast cancer cells. BMC Cancer 14539 (doi:10.1186/1471-2407-14-539)

Morelli C, Lanzino M, Garofalo C, Maris P, Brunelli E, Casaburi I, Catalano S, Bruno R, Sisci D \& Ando S 2010 Akt2 inhibition enables the forkhead transcription factor FoxO3a to have a repressive role in estrogen receptor $\alpha$ transcriptional activity in breast cancer cells. Molecular and Cellular Biology 30 857-870. (doi:10.1128/МСB.00824-09)

Mori M, Vignaroli G, Cau Y, Dinic J, Hill R, Rossi M, Colecchia D, Pesic M, Link W, Chiariello M et al. 2014 Discovery of 14-3-3 protein-protein interaction inhibitors that sensitize multidrug-resistant cancer cells to doxorubicin and the Akt inhibitor GSK690693. ChemMedChem 9 973-983. (doi:10.1002/cmdc.201400044)

Nowak K, Killmer K, Gessner C \& Lutz W 2007 E2F-1 regulates expression of FOXO1 and FOXO3a. Biochimica et Biophysica Acta 1769 244-252. (doi:10.1016/j.bbaexp.2007.04.001)

O'Hurley G, Daly E, O'Grady A, Cummins R, Quinn C, Flanagan L, Pierce A, Fan Y, Lynn MA, Rafferty M et al. 2014 Investigation of molecular alterations of AKT-3 in triple-negative breast cancer. Histopathology 64 660-670. (doi:10.1111/his.12313)

Osborne CK \& Schiff R 2011 Mechanisms of endocrine resistance in breast cancer. Annual Review of Medicine 62 233-247. (doi:10.1146/annurevmed-070909-182917)

Paik JH, Kollipara R, Chu G, Ji H, Xiao Y, Ding Z, Miao L, Tothova Z, Horner JW, Carrasco DR et al. 2007 FoxOs are lineage-restricted redundant tumor suppressors and regulate endothelial cell homeostasis. Cell 128 309-323. (doi:10.1016/j.cell.2006.12.029)

Park E, Gong EY, Romanelli MG \& Lee K 2012 Suppression of estrogen receptor- $\alpha$ transactivation by thyroid transcription factor- 2 in breast cancer cells. Biochemical and Biophysical Research Communications $\mathbf{4 2 1}$ 532-537. (doi:10.1016/j.bbrc.2012.04.039)

Parry P, Wei Y \& Evans G 1994 Cloning and characterization of the $t(\mathrm{X} ; 11)$ breakpoint from a leukemic cell line identify a new member of the forkhead gene family. Genes, Chromosomes \& Cancer 11 79-84. (doi:10.1002/gcc.2870110203)

Pearce LR, Komander D \& Alessi DR 2010 The nuts and bolts of AGC protein kinases. Nature Reviews. Molecular Cell Biology 11 9-22. (doi:10.1038/ nrm2822)

Perou CM 2011 Molecular stratification of triple-negative breast cancers. Oncologist 16 (Suppl 1) 61-70. (doi:10.1634/theoncologist.2011-S1-61)

Perou CM, Sorlie T, Eisen MB, van de Rijn M, Jeffrey SS, Rees CA, Pollack JR, Ross DT, Johnsen H, Akslen LA et al. 2000 Molecular portraits of human breast tumours. Nature 406 747-752. (doi:10.1038/35021093)

Piccart M, Hortobagyi GN, Campone M, Pritchard KI, Lebrun F, Ito Y, Noguchi S, Perez A, Rugo HS, Deleu I et al. 2014 Everolimus plus exemestane for hormone-receptor-positive, human epidermal growth factor receptor-2-negative advanced breast cancer: overall survival results from BOLERO-2†. Annals of Oncology 25 2357-2362. (doi:10.1093/annonc/mdu456)

Plas DR \& Thompson CB 2003 Akt activation promotes degradation of tuberin and FOXO3a via the proteasome. Journal of Biological Chemistry 278 12361-12366. (doi:10.1074/jbc.M213069200)

Potente M, Urbich C, Sasaki K, Hofmann WK, Heeschen C, Aicher A, Kollipara R, DePinho RA, Zeiher AM \& Dimmeler S 2005 Involvement of Foxo transcription factors in angiogenesis and postnatal neovascularization. Journal of Clinical Investigation 115 2382-2392. (doi:10.1172/ JCI23126)

Pritchard KI, Burris HA III, Ito Y, Rugo HS, Dakhil S, Hortobagyi GN, Campone M, Csoszi T, Baselga J, Puttawibul P et al. 2013 Safety and efficacy of everolimus with exemestane vs. exemestane alone in elderly patients with HER2-negative, hormone receptor-positive breast cancer in BOLERO-2. Clinical Breast Cancer 13 421-432.e8. (doi:10.1016/j.clbc. 2013.08.011)

Rena G, Woods YL, Prescott AR, Peggie M, Unterman TG, Williams MR \& Cohen P 2002 Two novel phosphorylation sites on FKHR that are critical for its nuclear exclusion. EMBO Journal 21 2263-2271. (doi:10.1093/emboj/21.9.2263)

Published by Bioscientifica Ltd. 
Rodon J, Dienstmann R, Serra V \& Tabernero J 2013 Development of PI3K inhibitors: lessons learned from early clinical trials. Nature Reviews. Clinical Oncology 10 143-153. (doi:10.1038/nrclinonc.2013.10)

Rugo HS 2015 Dosing and safety implications for oncologists when administering everolimus to patients with hormone receptor-positive breast cancer. Clinical Breast Cancer [in press]. (doi:10.1016/j.clbc.2015. 09.004)

Schmitt-Ney M \& Camussi G 2015 The PAX3-FOXO1 fusion protein present in rhabdomyosarcoma interferes with normal FOXO activity and the TGF- $\beta$ pathway. PLOS ONE 10 e0121474. (doi:10.1371/journal. pone.0121474)

Schuur ER, Loktev AV, Sharma M, Sun Z, Roth RA \& Weigel RJ 2001 Liganddependent interaction of estrogen receptor- $\alpha$ with members of the forkhead transcription factor family. Journal of Biological Chemistry $\mathbf{2 7 6}$ 33554-33560. (doi:10.1074/jbc.M105555200)

Seton-Rogers S 2015 Breast cancer: untangling the role of progesterone receptors. Nature Reviews. Cancer 15 456. (doi:10.1038/nrc3991)

Shajahan-Haq AN, Cook KL, Schwartz-Roberts JL, Eltayeb AE, Demas DM, Warri AM, Facey CO, Hilakivi-Clarke LA \& Clarke R 2014 MYC regulates the unfolded protein response and glucose and glutamine uptake in endocrine resistant breast cancer. Molecular Cell 13 239. (doi:10.1186/ 1476-4598-13-239)

Shang Y \& Brown M 2002 Molecular determinants for the tissue specificity of SERMs. Science 295 2465-2468. (doi:10.1126/science.1068537)

Shang Y, Hu X, DiRenzo J, Lazar MA \& Brown M 2000 Cofactor dynamics and sufficiency in estrogen receptor-regulated transcription. Cell 103 843-852. (doi:10.1016/S0092-8674(00)00188-4)

Siegel R, Ward E, Brawley O \& Jemal A 2011 Cancer statistics, 2011: the impact of eliminating socioeconomic and racial disparities on premature cancer deaths. CA: A Cancer Journal for Clinicians 61 212-236. (doi:10.3322/caac.20121)

Simoncini T, Hafezi-Moghadam A, Brazil DP, Ley K, Chin WW \& Liao JK 2000 Interaction of oestrogen receptor with the regulatory subunit of phosphatidylinositol-3-OH kinase. Nature 407 538-541. (doi:10.1038/ 35035131)

Sisci D, Maris P, Cesario MG, Anselmo W, Coroniti R, Trombino GE, Romeo F, Ferraro A, Lanzino M, Aquila S et al. 2013 The estrogen receptor $\alpha$ is the key regulator of the bifunctional role of FoxO3a transcription factor in breast cancer motility and invasiveness. Cell Cycle 12 3405-3420. (doi:10.4161/cc.26421)

Stal O, Perez-Tenorio G, Akerberg L, Olsson B, Nordenskjold B, Skoog L \& Rutqvist LE 2003 Akt kinases in breast cancer and the results of adjuvant therapy. Breast Cancer Research 5 R37-R44. (doi:10.1186/ bcr569)

Sublett JE, Jeon IS \& Shapiro DN 1995 The alveolar rhabdomyosarcoma PAX3/FKHR fusion protein is a transcriptional activator. Oncogene 11 $545-552$.

Sundaresan NR, Gupta M, Kim G, Rajamohan SB, Isbatan A \& Gupta MP 2009 Sirt3 blocks the cardiac hypertrophic response by augmenting Foxo3a-dependent antioxidant defense mechanisms in mice. Journal of Clinical Investigation 119 2758-2771. (doi:10.1172/JCI39162)

Thorpe LM, Yuzugullu H \& Zhao JJ 2015 PI3K in cancer: divergent roles of isoforms, modes of activation and therapeutic targeting. Nature Reviews. Cancer 15 7-24. (doi:10.1038/nrc3860)

Tokunaga E, Kimura Y, Oki E, Ueda N, Futatsugi M, Mashino K, Yamamoto M, Ikebe M, Kakeji Y, Baba $\mathrm{H}$ et al. 2006 Akt is frequently activated in HER2/neu-positive breast cancers and associated with poor prognosis among hormone-treated patients. International Journal of Cancer 118 284-289. (doi:10.1002/ijc.21358)

Tokunaga E, Hisamatsu Y, Tanaka K, Yamashita N, Saeki H, Oki E, Kitao H \& Maehara Y 2014 Molecular mechanisms regulating the hormone sensitivity of breast cancer. Cancer Science 105 1377-1383. (doi:10.1111/cas.12521)

Turner N, Pearson A, Sharpe R, Lambros M, Geyer F, Lopez-Garcia MA, Natrajan R, Marchio C, Iorns E, Mackay A et al. 2010 FGFR1 amplification drives endocrine therapy resistance and is a therapeutic target in breast cancer. Cancer Research 70 2085-2094. (doi:10.1158/ 0008-5472.CAN-09-3746)

Tzahar E, Waterman H, Chen X, Levkowitz G, Karunagaran D, Lavi S, Ratzkin BJ \& Yarden Y 1996 A hierarchical network of interreceptor interactions determines signal transduction by Neu differentiation factor/neuregulin and epidermal growth factor. Molecular and Cellular Biology 16 5276-5287. (doi:10.1128/MCB.16.10.5276)

Wang CX, Koay DC, Edwards A, Lu Z, Mor G, Ocal IT \& Digiovanna MP 2005 In vitro and in vivo effects of combination of trastuzumab (Herceptin) and tamoxifen in breast cancer. Breast Cancer Research and Treatment 92 251-263. (doi:10.1007/s10549-005-3375-z)

Wang F, Marshall CB, Yamamoto K, Li GY, Plevin MJ, You H, Mak TW \& Ikura M 2008 Biochemical and structural characterization of an intramolecular interaction in FOXO3a and its binding with p53. Journal of Molecular Biology 384 590-603. (doi:10.1016/ j.jmb.2008.09.025)

Wang F, Marshall CB, Li GY, Yamamoto K, Mak TW \& Ikura M 2009 Synergistic interplay between promoter recognition and CBP/p300 coactivator recruitment by FOXO3a. ACS Chemical Biology 4 1017-1027. (doi:10.1021/cb900190u)

Wang F, Marshall CB, Yamamoto K, Li GY, Gasmi-Seabrook GM, Okada H, Mak TW \& Ikura M 2012a Structures of KIX domain of CBP in complex with two FOXO3a transactivation domains reveal promiscuity and plasticity in coactivator recruitment. PNAS 109 6078-6083. (doi:10.1073/pnas.1119073109)

Wang F, Chan CH, Chen K, Guan X, Lin HK \& Tong Q 2012b Deacetylation of FOXO3 by SIRT1 or SIRT2 leads to Skp2-mediated FOXO3 ubiquitination and degradation. Oncogene 31 1546-1557. (doi:10.1038/onc.2011.347)

Wang YQ, Cao Q, Wang F, Huang LY, Sang TT, Liu F \& Chen SY 2015 SIRT1 protects against oxidative stress-induced endothelial progenitor cells apoptosis by inhibiting FOXO3a via FOXO3a ubiquitination and degradation. Journal of Cellular Physiology 230 2098-2107. (doi:10.1002/jcp.24938)

Webb AE \& Brunet A 2014 FOXO transcription factors: key regulators of cellular quality control. Trends in Biochemical Sciences 39 159-169. (doi:10.1016/j.tibs.2014.02.003)

Weigel D \& Jackle H 1990 The fork head domain: a novel DNA binding motif of eukaryotic transcription factors? Cell 63 455-456. (doi:10.1016/0092-8674(90)90439-L)

Weigel D, Jurgens G, Kuttner F, Seifert E \& Jackle H 1989 The homeotic gene fork head encodes a nuclear protein and is expressed in the terminal regions of the Drosophila embryo. Cell 57 645-658. (doi:10.1016/0092-8674(89)90133-5)

Wijchers PJ, Burbach JP \& Smidt MP 2006 In control of biology: of mice, men and Foxes. Biochemical Journal 397 233-246. (doi:10.1042/ BJ20060387)

Wondisford AR, Xiong L, Chang E, Meng S, Meyers DJ, Li M, Cole PA \& He L 2014 Control of Foxo1 gene expression by co-activator P300. Journal of Biological Chemistry 289 4326-4333. (doi:10.1074/ jbc.M113.540500)

Wright TM, Wardell SE, Jasper JS, Stice JP, Safi R, Nelson ER \& McDonnell DP 2014 Delineation of a FOXA1/ER $\alpha /$ AGR2 regulatory loop that is dysregulated in endocrine therapy-resistant breast cancer. Molecular Cancer Research 12 1829-1839. (doi:10.1158/ 1541-7786.MCR-14-0195)

Yang JY, Zong CS, Xia W, Yamaguchi H, Ding Q, Xie X, Lang JY, Lai CC, Chang CJ, Huang WC et al. 2008 ERK promotes tumorigenesis by inhibiting FOXO3a via MDM2-mediated degradation. Nature Cell Biology 10 138-148. (doi:10.1038/ncb1676)

Yardley DA, Noguchi S, Pritchard KI, Burris HA III, Baselga J, Gnant M, Hortobagyi GN, Campone M, Pistilli B, Piccart M et al. 2013 Everolimus plus exemestane in postmenopausal patients with $\mathrm{HR}(+)$ breast cancer: BOLERO-2 final progression-free survival analysis. Advances in Therapy 30 870-884. (doi:10.1007/s12325-013-0060-1) 
Yori JL, Lozada KL, Seachrist DD, Mosley JD, Abdul-Karim FW, Booth CN, Flask CA \& Keri RA 2014 Combined SFK/mTOR inhibition prevents rapamycin-induced feedback activation of AKT and elicits efficient tumor regression. Cancer Research 74 4762-4771. (doi:10.1158/00085472.CAN-13-3627)

Yuan Z, Becker EB, Merlo P, Yamada T, DiBacco S, Konishi Y, Schaefer EM \& Bonni A 2008 Activation of FOXO1 by Cdk1 in cycling cells and postmitotic neurons. Science 319 1665-1668. (doi:10.1126/science. 1152337)

Zhang F \& Kelly WL 2012 In vivo production of thiopeptide variants. Methods in Enzymology 516 3-24. (doi:10.1016/B978-0-12-394291-3. 00022-8)

Zhang Y, Gan B, Liu D \& Paik JH 2011 FoxO family members in cancer. Cancer Biology \& Therapy 12 253-259. (doi:10.4161/cbt.12.4.15954)

Zhao HH, Herrera RE, Coronado-Heinsohn E, Yang MC, Ludes-Meyers JH, Seybold-Tilson KJ, Nawaz Z, Yee D, Barr FG, Diab SG et al. 2001
Forkhead homologue in rhabdomyosarcoma functions as a bifunctional nuclear receptor-interacting protein with both coactivator and corepressor functions. Journal of Biological Chemistry 276 27907-27912. (doi:10.1074/jbc.M104278200)

Zhou X, Tan M, Stone Hawthorne V, Klos KS, Lan KH, Yang Y, Yang W, Smith TL, Shi D \& Yu D 2004 Activation of the Akt/mammalian target of rapamycin/4E-BP1 pathway by ErbB2 overexpression predicts tumor progression in breast cancers. Clinical Cancer Research $106779-6788$. (doi:10.1158/1078-0432.CCR-04-0112)

Ziegler SF 2006 FOXP3: of mice and men. Annual Review of Immunology 24 209-226. (doi:10.1146/annurev.immunol.24.021605.090547)

Zou Y, Tsai WB, Cheng CJ, Hsu C, Chung YM, Li PC, Lin SH \& Hu MC 2008 Forkhead box transcription factor FOXO3a suppresses estrogendependent breast cancer cell proliferation and tumorigenesis. Breast Cancer Research 10 R21. (doi:10.1186/bcr1872)

Received in final form 17 November 2015

Accepted 26 November 2015

Made available online as an Accepted Preprint

26 November 2015
(C) 2016 Society for Endocrinology Printed in Great Britain
Published by Bioscientifica Ltd. 